\title{
Review \\ On-Chip Integrated Photonic Devices Based on Phase Change Materials
}

\author{
Muhammad Shemyal Nisar ${ }^{1,2}{ }^{\oplus}$, Xing Yang ${ }^{1}$, Liangjun Lu ${ }^{1,2, *}$, Jianping Chen ${ }^{1,2}$ and Linjie Zhou ${ }^{1,2}$ \\ 1 State Key Laboratory of Advanced Optical Communication Systems and Networks, Shanghai Key Lab of \\ Navigation and Location Services, Shanghai Institute for Advanced Communication and Data Science, \\ Department of Electronic Engineering, Shanghai Jiao Tong University, Shanghai 200240, China; \\ mshemyalnisar@sjtu.edu.cn (M.S.N.); yangxing@sjtu.edu.cn (X.Y.); jpchen62@sjtu.edu.cn (J.C.); \\ ljzhou@sjtu.edu.cn (L.Z.) \\ 2 SJTU-Pinghu Institute of Intelligent Optoelectronics, Pinghu 314200, China \\ * Correspondence: luliangjun@sjtu.edu.cn
}

check for updates

Citation: Nisar, M.S.; Yang, X.; Lu, L.; Chen, J.; Zhou, L. On-Chip Integrated Photonic Devices Based on Phase Change Materials. Photonics 2021, 8 , 205. https://doi.org/10.3390/ photonics 8060205

Received: 19 May 2021

Accepted: 1 June 2021

Published: 7 June 2021

Publisher's Note: MDPI stays neutral with regard to jurisdictional claims in published maps and institutional affiliations.

Copyright: (c) 2021 by the authors. Licensee MDPI, Basel, Switzerland. This article is an open access article distributed under the terms and conditions of the Creative Commons Attribution (CC BY) license (https:// creativecommons.org/licenses/by/ $4.0 /)$

\begin{abstract}
Phase change materials present a unique type of materials that drastically change their electrical and optical properties on the introduction of an external electrical or optical stimulus. Although these materials have been around for some decades, they have only recently been implemented for on-chip photonic applications. Since their reinvigoration a few years ago, on-chip devices based on phase change materials have been making a lot of progress, impacting many diverse applications at a very fast pace. At present, they are found in many interesting applications including switches and modulation; however, phase change materials are deemed most essential for next-generation low-power memory devices and neuromorphic computational platforms. This review seeks to highlight the progress thus far made in on-chip devices derived from phase change materials including memory devices, neuromorphic computing, switches, and modulators.
\end{abstract}

Keywords: phase change material; integrated photonics; neuromorphic computing; phase change memory devices

\section{Introduction}

Light-matter interaction leads the electric charges in the material to oscillate due to the incident light (electromagnetic) waves. These oscillating charged particles under the incident light become a source of scattered light that interacts with neighbouring charged particles. This implies that the response of each charged particle is from a superposition of all the incident waves including the original incident wave and all of the subsequently scattered waves. At the macro-level, these interactions are manifested in the refractive index of the said material [1]. Given the centrality of the material refractive index, most photonic devices operate by microscale distribution of the refractive index in such a way to achieve the desired macroscopic results [2,3].

Phase change materials (PCMs) are a class of materials with interesting properties, which make them important for the development of various next-generation photonic devices. Their importance is due to phase change materials exhibiting at least two distinct phase states, between which the material can be reversibly switched. These phase states are due to stable and metastable atomic and crystal configurations, resulting in distinct electronic and optical properties [4], such as resistance and refractive index, respectively. As the change in resistance pertains to the domain of electronics, its utilization and devices are outside the scope of this work. This work only considers photonic applications and is, thus, restricted to refractive index switching.

Once a dormant area of research, PCMs were catapulted into the spotlight with the development of compact disc (CD), digital versatile disc (DVD), and Blu-ray disc (BD) that used $\mathrm{GeTe}-\mathrm{Sb}_{2} \mathrm{Te}_{3}$ (GST) and near-field optics as a means for tertiary data storage $[4,5]$. 
Subsequent advancements in optical devices have seen the increasing use of PCMs, as the multiplicity of reversibly switchable stable phases with considerably different refractive indices makes phase change materials an attractive choice for a variety of tasks including tuning [6], switching $[7,8]$, beam steering [9], memory devices $[10,11]$, computational memory devices [12], electro-absorption modulation [13,14], metasurfaces $[15,16]$, and neuromorphic computing $[17,18]$.

In this review, we discuss the recent advancements in on-chip optical devices that utilize phase change materials. To this end, this review presents different kinds of phase change materials and a limited discussion on the theory of phase change among different sorts of material. Then, we discuss different applications of phase change materials including phase change memories, in-memory and neuromorphic computing using PCM, and phase-change metasurfaces; lastly, we present the discussion and outlook.

\section{Phase Change Materials}

PCMs are a special material that exists in at least two different phases, frequently labeled as amorphous and crystalline. These phases are generally a result of rearrangement of the crystal structure of the material $[19,20]$. Although most other materials do also have amorphous and crystalline phases, the advantage of PCMs lies in the fact that both phases have different crystal structures, bringing about a considerable change in the refractive index [21]. As an example, silicon dioxide does also exist in amorphous and crystalline phases; however, due to their same crystal structure, there is only an insignificant difference in their refractive indices, and it is not regarded as a PCM [21]. On the other hand, octahedral amorphous GST becomes rhombohedral upon switching to crystalline GST [4], leading to a considerable change in refractive index. A contrasting refractive index and reversible switching are the two properties of PCMs that make them useful for optical devices.

While GST remains the most ubiquitous PCM so far [22], there has been research on other materials as a viable alternative platform for various applications. These phase change materials can be divided into four broad categories of chalcogenides, transition metal oxides, organic, and silicon. Some of the important properties of important PCMs from these categories are listed in Table 1. Additionally, some experiments have also been reported using hybrids. Among all these categories, other than some specific requirements for individual applications, for the PCM to be useful for optical devices, it should have the following properties $[4,5]$ :

- Significant contrast in refractive indices of different phases;

- Rapid switching;

- Chemical stability;

- Reversibly switchable between phases for a large number of cycles.

- Long cycling endurance, which leads to a large number of cycles.

Table 1. Properties of some of the PCMs where complex refractive indices for amorphous and crystalline phases are calculated for the wavelength of $1550 \mathrm{~nm}$. The source of data are from [23] for GST-225, [24] for $\mathrm{Sb}_{2} \mathrm{~S}_{3}$ and $\mathrm{Sb}_{2} \mathrm{Se}_{3}$, [25] for GSST, [26] for $\mathrm{VO}_{2}$, and [27-29] for Si.

\begin{tabular}{ccccc}
\hline PCM & $\begin{array}{c}\text { Complex R.I. } \\
\text { (Amorphous) }\end{array}$ & $\begin{array}{c}\text { Complex R.I. } \\
\text { (Crystalline) }\end{array}$ & Transition Temp. & Volatile \\
\hline $\mathrm{GST}-225$ & $4.6+0.18 i$ & $7.2+1.9 i$ & $600^{\circ} \mathrm{C}$ & No \\
$\mathrm{Sb}_{2} \mathrm{~S}_{3}$ & $2.712+0 i$ & $3.308+0 i$ & $270^{\circ} \mathrm{C}$ & No \\
$\mathrm{Sb}_{2} \mathrm{SS}_{3}$ & $3.285+0 i$ & $4.050+0 i$ & $200^{\circ} \mathrm{C}$ & No \\
$\mathrm{GSST}$ & $3.325+0.00018 i$ & $5.083+0.35 i$ & $250^{\circ} \mathrm{C}$ & No \\
$\mathrm{VO}_{2}$ & $2.75+0.4 i$ & $2.1+1.3 i$ & $68^{\circ} \mathrm{C}$ & Yes \\
$\mathrm{Si}$ & $3.4858+0 i$ & $3.487+0 i$ & $677^{\circ} \mathrm{C}$ & No \\
\hline
\end{tabular}




\subsection{Chalcogenides}

Chalcogenides are compounds between a chalcogen element (such as sulfur, selenium, tellurium, and polonium) and one or more metals. They generally undergo octahedral to rhombohedral crystalline structure on switching as shown in Figure 1. A typical chalcogenide PCM is GST [30,31], which has many varieties depending upon the concentration of constituent elements, but GST-225 (marked in red in Figure 1a) is the most useful of them all. In addition to GST, there are other chalcogenide PCMs, including GeTe [32], $\mathrm{Sb}_{2} \mathrm{Te}$ [32], $\mathrm{Ag}_{5} \mathrm{In}_{5} \mathrm{Sb}_{60} \mathrm{Te}_{30}$ (AIST) [33], and GSST [34,35]. These materials exhibit strong resonance bonding in their crystalline state, which is the reason for the considerable difference in the optical properties compared to other materials [36]. Comparisons of GST, GSST, and $\mathrm{Sb}_{2} \mathrm{~S}_{3}$ properties can be verified in Figure 1c-e. As a group, all of them have small electronegativity differences, which is the reason for their covalent bonding, and both of their phases are nonvolatile at room temperature, which is an advantage for certain applications such as memory devices.

(a)

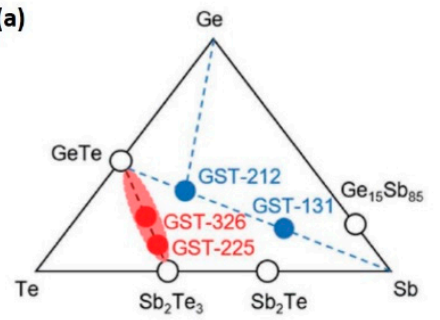

(b) Amorphous

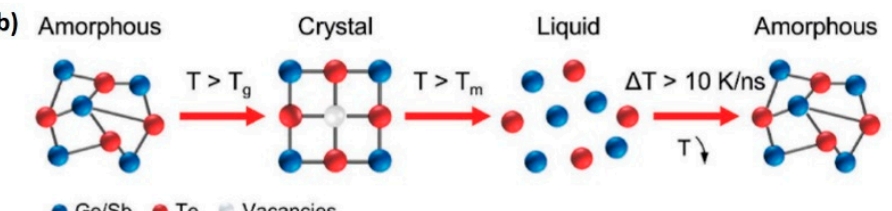

(c)

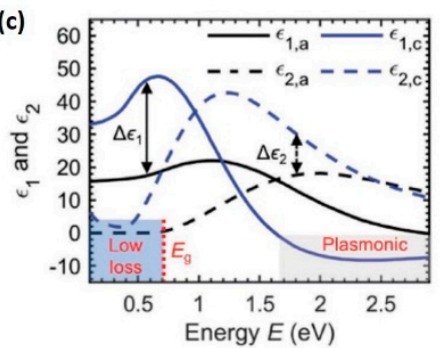

- Ge/Sb - Te Eacancies

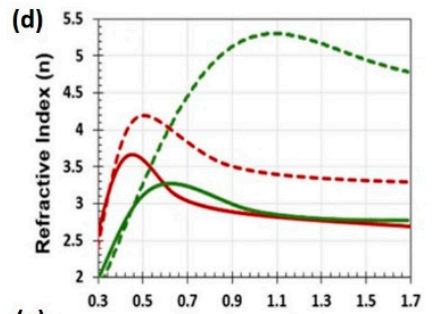

(e)

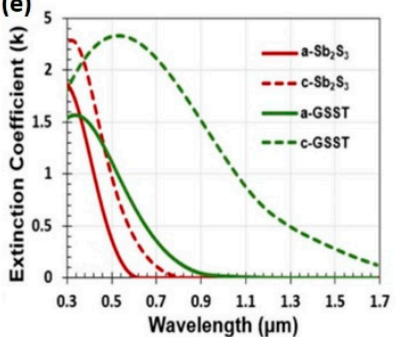

Figure 1. Chalcogenide phase change materials. (a) Ternary phase diagram of $\mathrm{Ge}-\mathrm{Sb}-\mathrm{Te}$ showing important pseudo-binary combination. Most frequently used $(\mathrm{GeTe})_{x}-\left(\mathrm{Sb}_{2} \mathrm{Te}_{3}\right)_{1-x}$ compounds such as GST-326 and GST-225 are labeled in red. (b) The typical structural transformation in GST-225 when it undergoes a phase transition from amorphous to crystalline to liquid and then back to amorphous. $\mathrm{T}_{\mathrm{g}}$ and $\mathrm{T}_{\mathrm{m}}$ are the glass transition temperature and melting temperature, respectively. (c) Dielectric function of GST-225 in the amorphous and crystalline phase. (d) Refractive index (n) and (e) extinction coefficient $(\mathrm{k})$ of the amorphous and crystalline state of $\mathrm{Sb}_{2} \mathrm{~S}_{3}$ and GSST. $((\mathbf{a}-\mathrm{c})$ reproduced with permission [21]; (d,e) reproduced with permission [37]).

$\mathrm{Sb}_{2} \mathrm{~S}_{3}$ and $\mathrm{Sb}_{2} \mathrm{Se}_{3}$ have been rather late entrants into the group of chalcogenide PCMs. Although some earlier work reported $\mathrm{Sb}_{2} \mathrm{~S}_{3}$ and $\mathrm{Sb}_{2} \mathrm{Se}_{3}$ as PCMs [38,39], subsequent works on chalcogenide PCMs largely ignored these materials $[4,32,40]$ until they were rediscovered as low-loss PCMs [24]. As can be observed in Figure 1c-e, in contrast with GST, which has a large absorption coefficient leading to large losses, $\mathrm{Sb}_{2} \mathrm{~S}_{3}$ was reported to have an absorption coefficient of zero at the operating wavelength of $1550 \mathrm{~nm}[24,37]$, while that of $\mathrm{Sb}_{2} \mathrm{Se}_{3}$ was also reported to be near zero at the wavelength of $1550 \mathrm{~nm}$ by Delaney [24]. As for the visible region, $\mathrm{Sb}_{2} \mathrm{~S}_{3}$ still retrains near-zero absorption as opposed to $\mathrm{Sb}_{2} \mathrm{Se}_{3}$, which shows a sharper rise in the absorption coefficient [40]. The property of low loss attracted renewed interest in these materials [41-46], for both on-chip and freespace applications. On the flip side, $\mathrm{Sb}_{2} \mathrm{~S}_{3}$ reportedly also undergoes larger size variation when switching from amorphous to the crystalline phase. This may be undesirable for certain applications.

Oxidation of the chalcogenide layer is a major problem among all of these chalcogenide materials which oxidize even at room temperature, leading to performance degradation 
over time. To prevent oxidation, a protective layer on top of the chalcogenide PCM layer is used. In the case of GST-225 and GSST, the Ge atoms deplete due to oxidation. A thin layer of indium tellurium oxide (ITO) is deposited on top of the GST patch [11] and GSST patch [25] to prevent oxidation. In the case of $\mathrm{Sb}_{2} \mathrm{~S}_{3}$ and $\mathrm{Sb}_{2} \mathrm{Se}_{3}$, a ZnS:SiO${ }_{2}(20 \%: 80 \%)$ layer is used on top which prevents the loss of the sulfur/selenium atom [24]. In some recent publications, Fang and his colleagues reported successfully using a silicon nitride $\left(\mathrm{Si}_{3} \mathrm{~N}_{4}\right)$ cap on top of $\mathrm{Sb}_{2} \mathrm{~S}_{3}$ PCM [47], while Faneca and colleagues also successfully demonstrated the use of an $\mathrm{Si}_{3} \mathrm{~N}_{4}$ cap on GST [48]. The method seems advantageous concerning the cost of the fabrication process and the complexity of the fabrication process, as deposition of $\mathrm{Si}_{3} \mathrm{~N}_{4}$ through plasma-enhanced chemical vapor deposition (PECVD) is a standardized practice.

\subsection{Transition Metal Oxides}

Transition metal oxides that undergo Mott transition (also called correlated materials) are the second most important category of PCMs in terms of volume of publications. Conductivity in Mott insulators such as vanadium dioxide $\left(\mathrm{VO}_{2}\right)$ is temperature-dependent as they transit from insulator to conductor when the temperature goes from low to high [36]. This transition in conductivity is accompanied by a transition in refractive index, making the materials useful for optical devices. Among them, vanadium oxide is the most popular that can reversibly switch between metallic rutile and two insulating monoclinic structures [49], depicted in Figure 2a. While all of the transition metal oxides show a similar structural transition, the structural transition does not always translate into electronic transition, leading to metallic and insulating phases as in $\mathrm{VO}_{2}$ and $\mathrm{NbO}_{2}$. Both states show different refractive indices and absorption coefficients. Typical values of refractive index and absorption coefficient for $\mathrm{VO}_{2}$ are shown in Figure $2 \mathrm{~b}, \mathrm{c}$, respectively. The temperature at which the switching takes place is called the transition point. These transition points in the correlated materials can be tuned by tuning the banding filling through doping [50]; for example, the $\mathrm{VO}_{2}$ transition point is at $68^{\circ} \mathrm{C}$, which can be further reduced even to room temperature by doping it with tungsten [36].

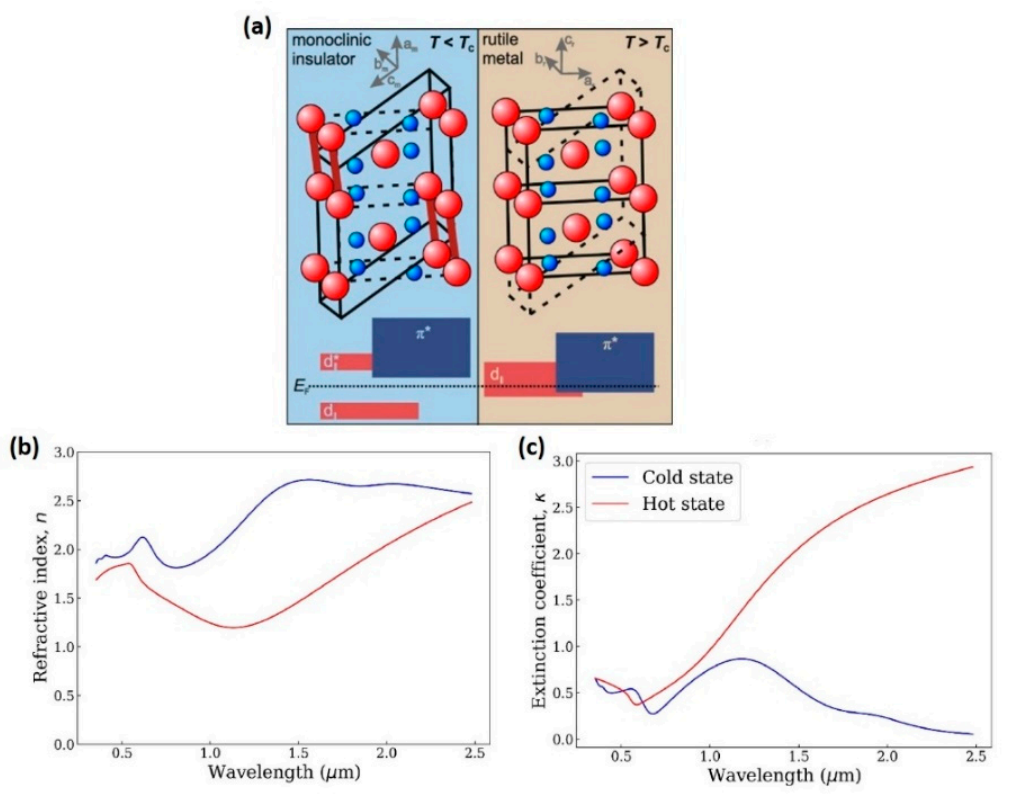

Figure 2. Transition metal oxide phase change material $\mathrm{VO}_{2}$. (a) Comparison of monoclinic and rutile crystallographic structures; the unit cells are indicated by solid lines. Vanadium atoms are represented by red balls; oxygen atoms are blue. The electronic band structure near the Fermi level is given at the bottom. (b) Refractive index and (c) extinction coefficient of $\mathrm{VO}_{2}$ in the cold and hot states showing a large change in refractive index and extinction coefficient with the temperature. ((a) reproduced with permission [51]; (b,c) reproduced with permission [52]). 
The temperature dependence of the metastable states means that the material is suitable for volatile applications. The material has been tested with on-chip devices such as optical switches [53], resonators [19], photonic and plasmonic waveguides [54], polarization converters $[55,56]$. The temperature can be changed through thermal, electrical, or optical means, but applications requiring faster switching should resort to electrical or optical switching as thermal means are slow.

Like GST, vanadium oxide also readily oxidizes from $\mathrm{VO}_{2}$ to $\mathrm{V}_{2} \mathrm{O}_{5}$ in air and, thus, requires a protective layer. Hydrophobic material hafnium dioxide $\left(\mathrm{HfO}_{2}\right)$ is usually used as the protective layer, which should completely cover the $\mathrm{VO}_{2}$ sample to protect it from oxidation as an unprotected cross-section of the film would also lead to performance degradation [57].

Although many research groups are actively involved in the development of $\mathrm{VO}_{2}$ based devices, some researchers have shown skepticism toward the applicability of $\mathrm{VO}_{2}-$ based systems in practical applications for their limited multilevel response, volatility, and complexity of fabrication [58]. This is probably also the reason for them not being as popular as chalcogenides.

\subsection{Organic Phase Change Materials}

Organic materials are predominantly made of carbon and hydrogen; however, neither these elements nor their compounds inherently exhibit phase change behavior. Therefore, phase change behavior is generally achieved through the interaction of cyclic compounds with other functional groups such as benzene, pyridine, and pyrrole [59]. Some experiments with functional groups containing transition elements have been successful [60].

Numerous organic materials have been used for memristive memory devices [61], switches [62], and neuromorphic computational platforms [63]. This includes pure organic materials in perovskite and non-perovskite forms [63], as well as hybrids with other metals or nonmetals $[64,65]$. All of these reported devices operate on the basis of a change in resistance through particle transfer leading to a switching action. As this review is focused on phase change materials useful for photonic applications, these platforms are out of the scope of this study.

On the other hand, many organic phase change materials including PNIPAM [66,67] or even doped carbon [59] do exist, which are thermally responsive. As these materials have temperature-dependent metastable states, they can theoretically be used for volatile applications in which $\mathrm{VO}_{2}$ is used. However, to date, there has been no report of using organic phase change materials for optical devices of this nature. We can speculate the reasons to be related to the insufficient contrast in refractive index as reported for PNIPAM [68], phase instability as reported for PNIPAM [69], slower response time [70], or a lack of interest among the research community for exploring organic phase change materials.

Some of the organic phase change materials with different functional groups are shown in Figure 3 with the hope that it could inspire some interest among the research community for organic phase change materials in the future. 


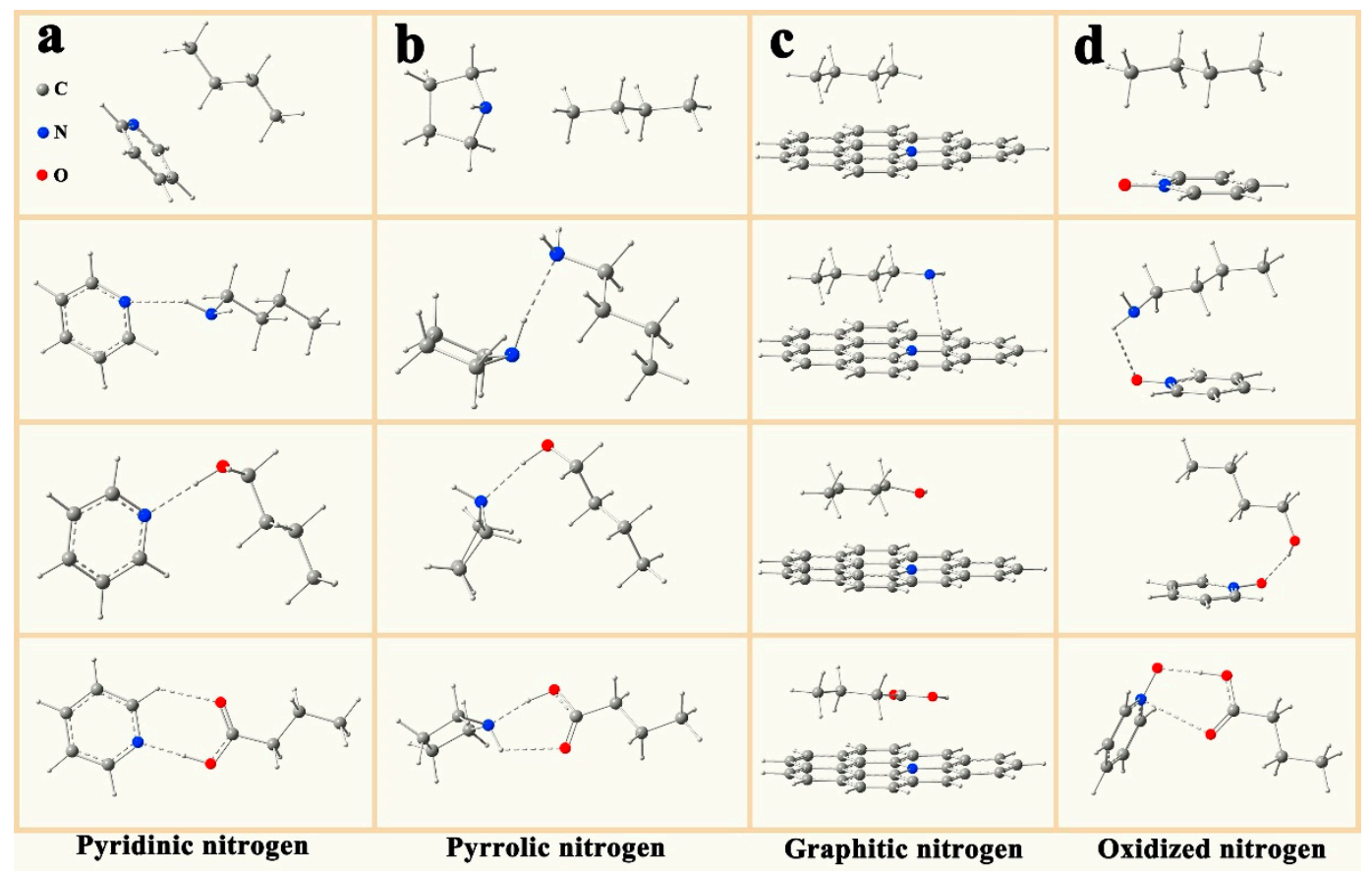

Figure 3. Optimized organic bimolecular configurations between different nitrogen species of N-doped hierarchical carbon and PCM molecules with different functional groups such as (a) Pyridinic nitrogen, (b) Pyrrolic nitrogen, (c) Graphitic nitrogen, and (d) Oxidized nitrogen (reproduced with permission [59]).

\subsection{Silicon}

Silicon is the most pervasively used material in the photonics industry, as well as the semiconductor industry at large [36], which can also behave as a phase change material. The ability to control the crystallinity of silicon by tuning the temperature during the low-pressure chemical vapor deposition (LPCVD) process has always been known. The transistor industry has been regularly producing crystalline silicon through the action of lasers, both pulsed lasers [71] and excimer lasers [72], in thin films, as well as bulk silicon.

These laser-based systems can crystallize and re-amorphize the silicon on the nanosecond time scale, and this process can be reversibly switched without any deformation. The change in refractive index and absorption coefficient brought about due to the silicon changing phase is not significant at the wavelength of $1.55 \mu \mathrm{m}$ [73]. However, the difference becomes comparatively large as the wavelength shortens to the visible regime, as shown in Figure 4. Some free-space visible-range proof-of-concept studies have also reported the use of silicon as a PCM [29,74]; however, at the time of writing this review, no demonstration of silicon as a PCM for integrated devices has been found. 

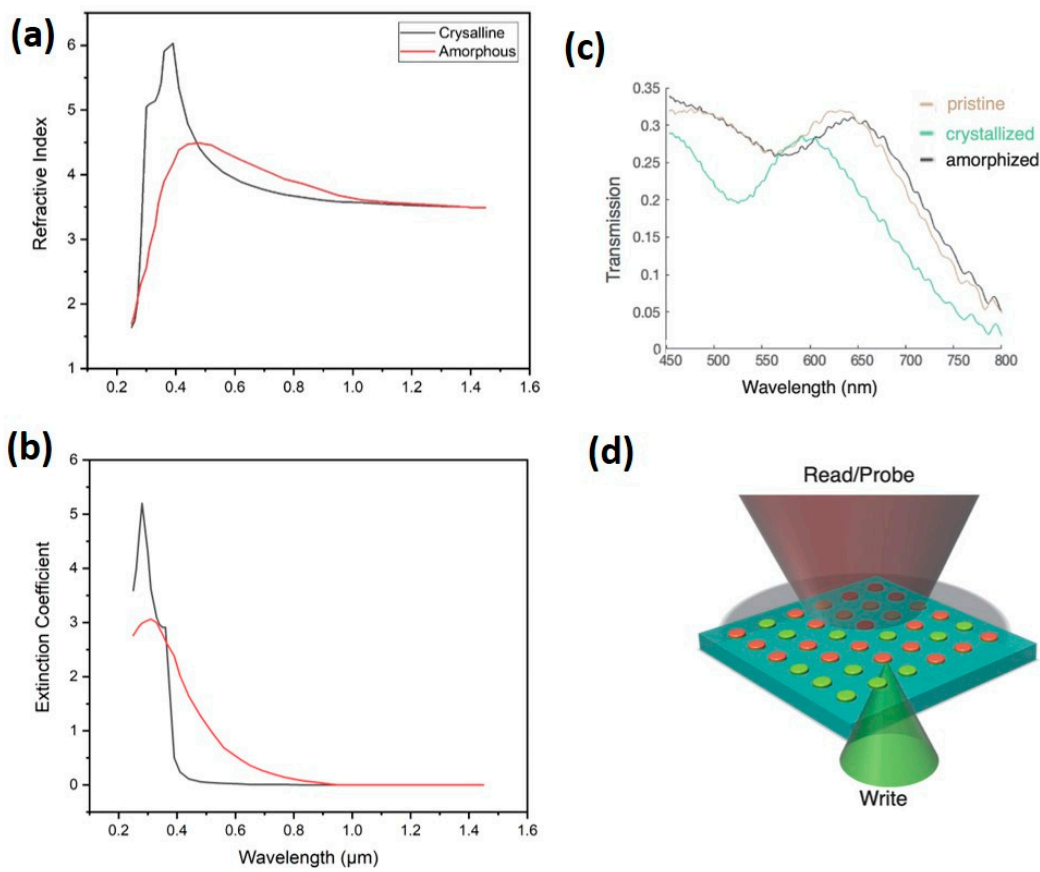

(d)

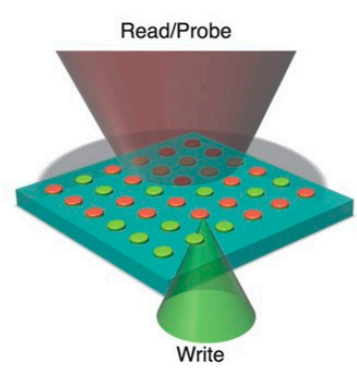

Figure 4. (a) Refractive index and (b) extinction coefficient of silicon in the crystalline and amorphous states showing a large change in refractive index and extinction coefficient in the UV and near-UV region, which is reduced to an insignificant difference as it reaches $1.5 \mu \mathrm{m}[27,28]$. (c) Transmission spectra of pristine a-Si nanodiscs, crystallized nanodiscs, and re-amorphized nanodiscs with $215 \mathrm{~nm}$ in diameter. (d) The conceptual pixel-addressable rewritable metasurface for optical wavefront control. ((c,d) Reproduced with permission [29]).

Having looked at all four categories of PCMs in detail, the pros and cons of each of the categories for integrated photonic applications are summarized in Table 2.

Table 2. Summary of pros and cons of PCM categories; the last two columns denote whether there has been a report in the literature concerning the use of each category for any type of photonic application or integrated photonic application.

\begin{tabular}{|c|c|c|c|c|}
\hline Category & Pros & Cons & $\begin{array}{c}\text { Used for } \\
\text { Photonic app. }\end{array}$ & $\begin{array}{c}\text { Used for } \\
\text { Integrated } \\
\text { Photonic app. }\end{array}$ \\
\hline Chalcogenide & $\begin{array}{l}\text { Fast switching, } \\
\text { nonvolatile }\end{array}$ & $\begin{array}{c}\text { High transition } \\
\text { temperature, } \\
\text { lossy }\end{array}$ & $\sqrt{ }$ & $\sqrt{ }$ \\
\hline $\begin{array}{c}\text { Transition metal } \\
\text { oxide }\end{array}$ & $\begin{array}{l}\text { Low transition } \\
\text { temperature, } \\
\text { volatile, fast } \\
\text { switching }\end{array}$ & $\begin{array}{l}\text { Require constant } \\
\text { energy, lossy }\end{array}$ & $\sqrt{ }$ & $\sqrt{ }$ \\
\hline Organic & $\begin{array}{l}\text { Low transition } \\
\text { temperature }\end{array}$ & $\begin{array}{l}\text { Low melting } \\
\text { point, slower } \\
\text { response, easily } \\
\text { combustible }\end{array}$ & $x$ & $x$ \\
\hline Silicon & $\begin{array}{c}\text { Ease of } \\
\text { fabrication, ease } \\
\text { of integration, } \\
\text { low loss }\end{array}$ & $\begin{array}{c}\text { No refractive } \\
\text { index contrast at } \\
\text { IR, } \\
\text { Highest } \\
\text { transition } \\
\text { temperature }\end{array}$ & $\sqrt{ }$ & $x$ \\
\hline
\end{tabular}




\section{Phase Switching}

The phase switching process can be seen at two levels. One is at the atomic level where the kinetics of the phase change process is studied. The other level is at the device level when the phase change is brought about by the designer of the system. The kinetics of crystallization for a phase change material in the amorphous phase can be divided into two categories of nucleation-dominated and growth-dominated [75].

Nucleation-dominated crystallization (shown in Figure 5a) takes place with small spots of crystalline material that are randomly distributed in the PCM. With the rise of the temperature, these nuclei grow until the whole of the PCM has crystallized [76]. A study conducted by Lee and his colleagues [76] found that chalcogenides such as GST crystallize through the nucleation-dominated process where the size distribution of the nuclei depends on the thermal treatment they received, which implies that the statistical status of nuclei distribution in as-deposited amorphous PCM is different to that in preannealed PCM. Moreover, their research into the nucleation process also found that, if the amount or volume of subcritical nuclei embedded in amorphous material is greater, the formation of a supercritical nucleus is easier and, thus, the time is shorter [76,77]. The result is that the nucleation process in GST is faster, thus making it a nucleation-dominated crystallization material.

(a)

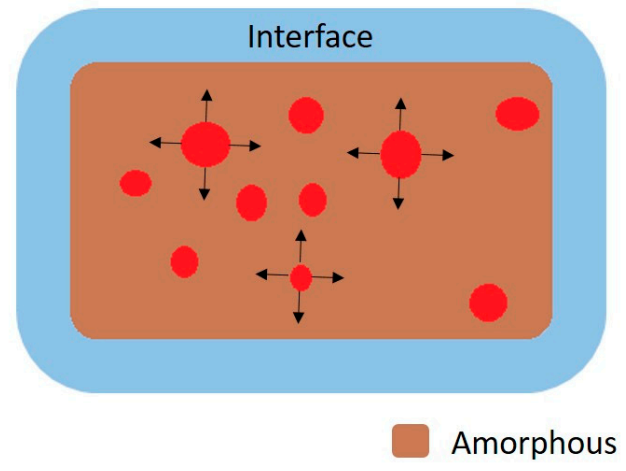

(b)

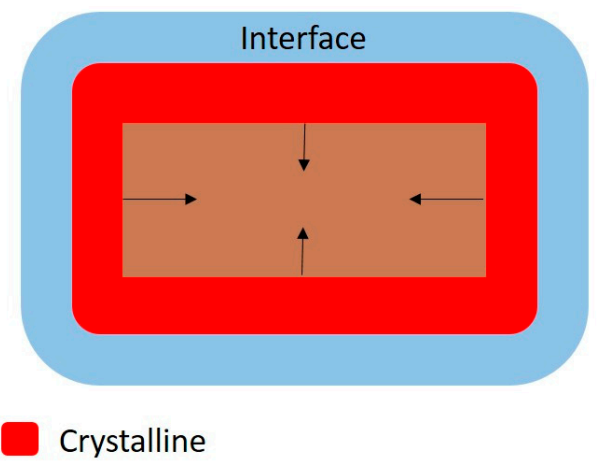

Figure 5. Two different kinetics of crystallization: (a) nucleation-dominated crystallization kinetics where there is a random distribution of islands of crystallinity that later expand; (b) growthdominated crystallization where the initial crystalline precipitate grows to include the rest of the amorphous material.

Growth-dominated crystallization (depicted in Figure 5b), on the other hand, is where the rate of growth of the crystalline region is more than the rate of nucleation. In such crystals, only a few nuclei precipitate when the amorphous material is annealed [75]; instead, the precipitated nuclei grow their boundaries to include the still amorphous region into the crystalline region [78]. A study conducted by Khulbe found that, in materials that are growth-dominated, there is a trade-off between incubation time and nucleation speed. The most important examples of materials showing growth-dominated crystallization are $\mathrm{Ag}$ and In-doped SbTe (AIST) [75].

At the device level, the underlying physics to achieve switching remains thermal; however, due to the sluggish response of the thermal systems, the PCM is not directly heated. Rather, to switch, either electrical means or optical means are used which achieve the temperature required for switching between crystalline and amorphous phases. Although some electro-thermal methods have also been improved recently through the use of devices such as graphene heaters [79], considered as a fundamental mechanism, there is a lag in switching speed [80]. Among these three means of switching, optical switching produces the fastest switching, followed by electrical switching, while thermal switching remains the slowest $[19,36]$. 
Another aspect connected with phase switching is the cycling endurance of the phase change material used for switching. The endurance refers to the number of cycles for which a particular material can be reversibly switched before its two phases (SET and RESET) become difficult to discriminate or the material simply does not switch [81,82]. Such recyclability, measured as the number of cycles of PCMs, is inversely related to the volume of the PCM used, as well as the method of switching adopted. According to Bez, at the fundamental level, there should not be any wear and tear of the material due to switching [83]. However, data show reduced resistive performance after $10^{8}-10^{10}$ cycles. An interesting finding by Raoux was that the number of cycles and the energy required to trigger the phase transition are inversely related [81]. With respect to the method of switching, GST is known to have a recyclability of higher than $10^{7}$ cycles when electrically switched, whereas it reduces to $10^{5}$ cycles when optical switching is employed [84].

\subsection{Electrical Switching}

Electrical switching is the older of the two methods of electrical and optical switching, and it also finds parallels in earlier technologies such as transistors and other concurrent technologies such as memristors $[85,86]$. For switching the PCM through electrical means, two different methods have been used. One method is to use an external electrical circuit that is generally connected to a heating element that generates heat through resistance to the current [7,87]. Examples of such systems are ITO heaters [88,89], silver heaters [80], and PIN heaters [90]. The other method is the approach used in memristors where current is used for achieving the phase change [7]. Schematics of the typical arrangements to achieve electrical switching with GST and $\mathrm{VO}_{2}$ as PCMs are shown in Figure 6a-c. The generated heat due to passing current can reversibly switch the state of the PCM unit placed on top of these photonic structures. After switching, when an optical signal passes through the waveguide under the PCM, the signal is evanescently coupled with the straddling PCM unit, leading to a change in the signal. So far, the literature has not revealed any phase change material-based photonic device that has in-line phase change material.

These electrical methods are advantageous, as the heating circuit and the optical circuit of the device are independent and separate from each other. This makes the device more controllable and can enable easier access to complex and multilayered optical circuits. Given that microelectronic technology is well established and mature, it helps in the design of electrically controlled devices. Additionally, as the external control circuitry is also electronic, it can be monolithically integrated. On the other hand, the electronic control circuit makes the devices bulky and increases the steps of fabrication linked to the final cost of the product. However, most importantly as per the current thrust of society toward energy conservation, the electronic method of switching is also wasteful in terms of energy, leading to higher cost per switch. Recently, some graphene-based models have been suggested (schematically shown in Figure 6b) due to their success in limiting the energy waste in electrically controlled PCM-based photonic devices [79,92]. 
(a)

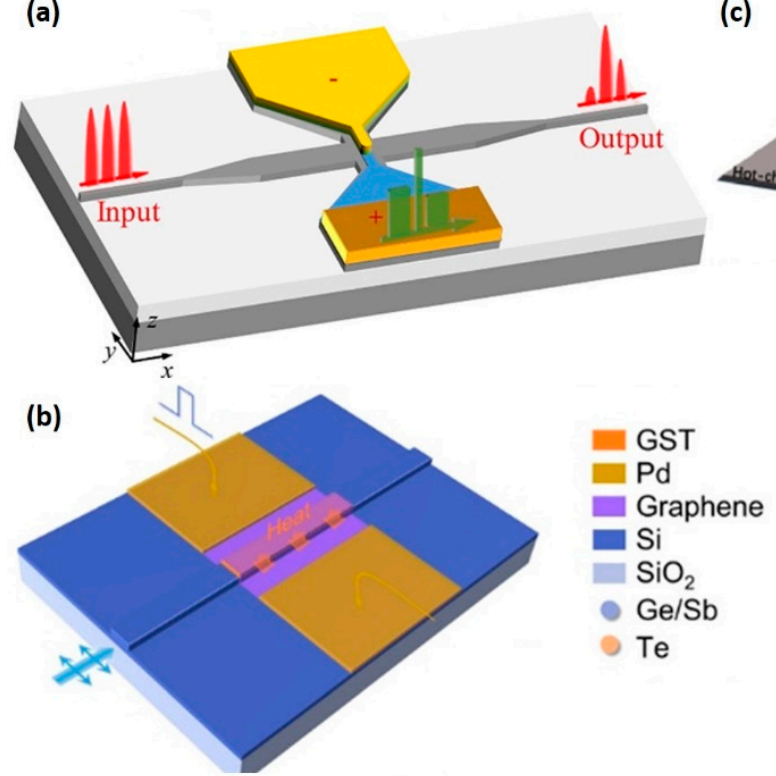

(c)

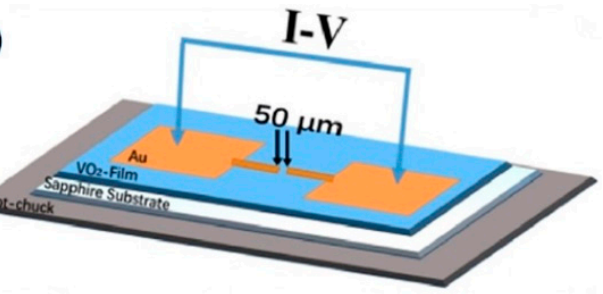

(d) IN

(e)

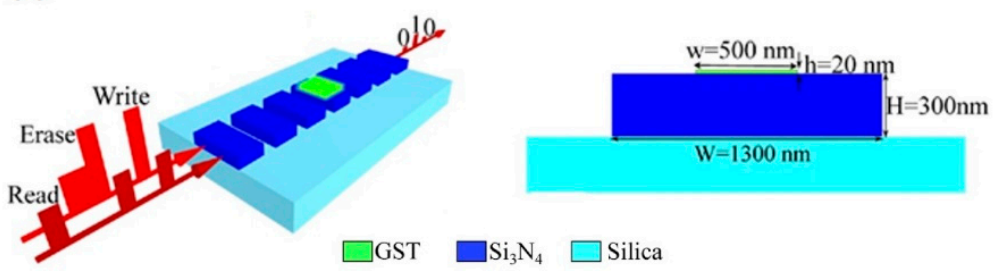

Figure 6. Various electrical and optical switching methods. (a) Electrical switching of GST on silicon waveguide using Au electrodes [91]. (b) Electrical switching of GST using Pd electrodes while using a graphene heater (reproduced with permission [92]). (c) Schematic of $\mathrm{VO}_{2}$ devices for electric field-driven metal-to-insulator transition (reproduced with permission [93]). (d) Schematic of PCM heating through control of surface plasmons polaritons with external optical excitation (reproduced with permission [82]). (e) Schematic of optically reconfigurable waveguide. High-power optical pulses are used to change the phase of the GST while low-power read pulses can transmit low or high transmittance values depending on the state of the GST deployed on top; (right) $2 \mathrm{D}$ cross-sectional view showing GST deployed on top of $\mathrm{Si}_{3} \mathrm{~N}_{4}$, which is switched through evanescent coupling [94].

\subsection{Optical Switching}

Optical switching, also called all-optical devices, on the other hand, is when an optical signal is used to bring about phase change in the PCM. Heat is generated by a high-energy laser pulse due to the opto-thermal effect, leading to switching in the linked phase change material [95]. This can be achieved through two different methods. One method is to use an external laser that is incident on the PCM unit from the far-field and excite it to achieve the switching [82,96]. This method is used for free-space devices, as well as on-chip devices, as shown in Figure 6d. Figure 6d shows that using plasmon polaritons for heat generation would ultimately lead to phase change of the PCM. The second method, which is used for on-chip devices, involves evanescent field coupling. In evanescent coupling, a control signal from a high-powered laser traverses through the on-chip photonic crystal and achieves a switch in the PCM deployed on top through the opto-thermal interaction of the evanescent field and the PCM, as shown in Figure 6e [97]. Although some devices with in-line PCM for certain applications have also been demonstrated [98], the large absorption coefficient in most PCMs currently in use has led to most designers resorting to evanescent coupling (schematically shown in Figure 6e). With the development of low-loss PCMs [41], the phase change material can be deployed in line. The in-line deployed PCM 
would increase the interaction volume of the PCM and the optical wave, leading to smaller device footprints.

The optical switching uses the same optical circuit that the signal would use, making the device design less bulky while also reducing the number of fabrication steps. Researchers, using optical switching, have reportedly achieved low-power switching using femtosecond lasers [9]. This is a promising result concerning lower energy targets. However, on the other hand, routing the optical signal to achieve the necessary phase change is a difficult task as fabricating three-dimensional photonic circuits is still not easily achievable with the current state of technology. Secondly, achieving switching in the traditional sense using low-loss PCM is difficult due to the low absorption loss of the material. Thus, accessing each PCM unit serially placed on a single waveguide individually is also problematic. While it may not be needed for certain applications such as those implementing Hebbian learning for artificial synapses [95,99], there are other situations where individual access is needed. This has led to some researchers addressing this problem through the use of novel designs such as grid structures [12] or through the use of wavelength division multiplexing with ring resonators straddling individual PCM unit cells [100]. Although promising, these systems are still far from being useful in practical devices.

On the topic of comparison between electrical switching and optical switching in GST-based silicon photonic switches, Zhang concluded that, for the amorphization process, optical switching is advantageous in terms of speed and energy efficiency. However, as alluded to earlier, for large-scale integration purposes, electrical switching is still advantageous as it does not require a complex routing circuit for the photonic circuit [101].

\section{Phase Change Memories}

Phase change memories can be regarded as the first and arguably most successful application of phase change materials, with CDs as a forerunner, followed by DVDs and BDs as the most popular tertiary memory devices up until recently [5]. The development of such phase change material-based memories can be traced back to the 1970s [102]. In one such work, Yamada and his colleagues [103] presented direct overwriting at the speed of nanoseconds using GST alloy. Despite the success and the early start, these applications were optically switched and not the on-chip applications of phase change materials.

On the on-chip front, the subsequent decades saw extensive developments in the electrically switched resistance-based phase change memories that were comparable with dynamic random access memory (DRAM), NAND based on not/and (NAND) logic gates [104], flash memory [105], and even a proposal for on-chip optical switches [106]. The high-density memory, presented as nonvolatile phase-change random access memory (PRAM), addressed the speed, scalability, and power consumption issues of DRAM [107-109].

The first all-optical on-chip phase change memory was proposed by placing a patch of GST-225 on an $\mathrm{Si}_{3} \mathrm{~N}_{4}$ ring resonator structure on silica. This was reported in 2012 by Pernice and Bhaskaran [10] (some of the details are shown in Table 3), whose group later also fabricated the sample but presented it as a tunable nanophotonic circuit, which was a building block on the way to creating a memory element [110]. Subsequently, a detailed analysis of the memory device made with a GST-225 patch on an $\mathrm{Si}_{3} \mathrm{~N}_{4}$ racetrack was presented in 2014, which is shown in Figure 7a [111]. Using the principle of change in absorption of GST [112], they showed that the Q-factor, the resonance wavelength, and the extinction ratio can be used to retrieve the state of GST, which is a memory element that can be switched on "a picosecond timescale" [111]. In a later work, the group demonstrated a multilevel cum multibit storage using multiple ring resonators coupled with a single waveguide, accessible through wavelength division multiplexing (WDM) [113]. The demonstrated device with an operating speed of $800 \mathrm{MHz}$ for the write operation could be improved to the gigahertz level using picosecond pulses. The reported device, with a footprint of $0.25 \mu \mathrm{m}^{2}$, demonstrated fast ( $\sim 500 \mathrm{ps}$ ) and low-power readout (480 fJ). This work is unique as it also showed the ability to accurately control the percentage of GST in the crystalline or amorphous state through the intensity of the writing 
pulse [112]. Using a slightly different architecture, an extensive 512 bit all-optical memory was also demonstrated to store a $16 \times 16$ bit image in grayscale with 2 bit resolution [100]. The device had a relatively large footprint of $1000 \times 2400 \mu \mathrm{m}^{2}$, which could be slightly reduced using a silicon substrate instead of $\mathrm{Si}_{3} \mathrm{~N}_{4}$.

Table 3. Major contributions in memory devices.

\begin{tabular}{|c|c|c|c|c|c|c|}
\hline Year & PCM & Main Features & All Optical & Speed & Footprint & Power \\
\hline 2012 [10] & GST & $\mathrm{Si}_{3} \mathrm{~N}_{4}$ ring resonator with GST patch & $\sqrt{ }$ & - & - & - \\
\hline 2014 [111] & GST & $\mathrm{Si}_{3} \mathrm{~N}_{4}$ ring resonator with GST patch & $\sqrt{ }$ & - & - & - \\
\hline 2015 [113] & GST & $\begin{array}{l}\mathrm{Si}_{3} \mathrm{~N}_{4} \text { multiple ring resonators with GST } \\
\text { patches coupled to a single waveguide } \\
\mathrm{Si}_{3} \mathrm{~N}_{4} \text { Photonic Memories and Logic }\end{array}$ & $\sqrt{ }$ & 500 ps & $0.25 \mu \mathrm{m}^{2}$ & $480 \mathrm{fJ}$ \\
\hline 2018 [114] & GST & $\begin{array}{l}\text { Operations using PWM for switching of } \\
\text { PCM. }\end{array}$ & $\sqrt{ }$ & - & - & - \\
\hline 2018 [115] & GST & $\begin{array}{l}\text { Logic "OR" and "NAND" implemented } \\
\qquad \mathrm{Si}_{3} \mathrm{~N}_{4}\end{array}$ & $x$ & $505 \mathrm{~ns}$ & - & $16 \mathrm{pJ}$ \\
\hline 2021 [25] & GSST & $\begin{array}{l}\text { Photonic integrated memory with } \\
\text { accuracy up to } 93 \%\end{array}$ & $x$ & $<1 \mathrm{ps}$ & $<4 \mu \mathrm{m}^{2}$ & - \\
\hline
\end{tabular}

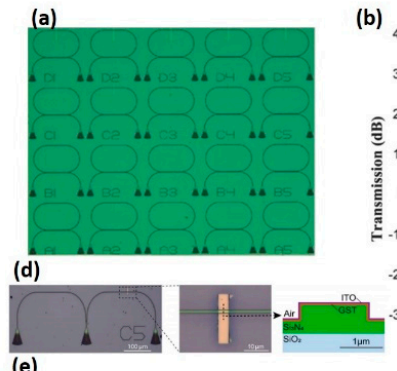

(e)

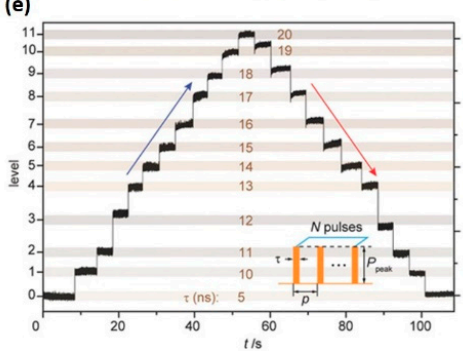

(b)

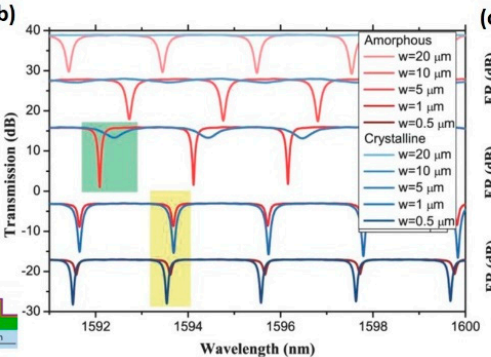

(f)

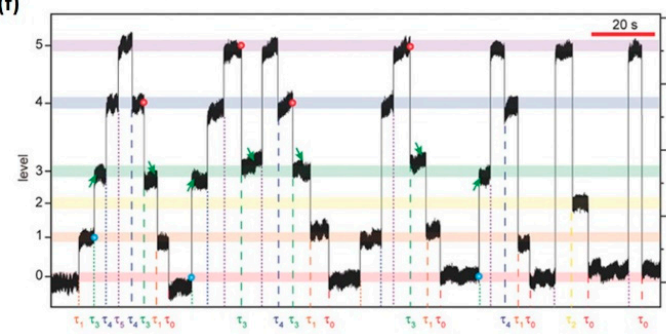

Figure 7. Implementation of phase change memories. (a) Microscopic image different memory elements. Along the horizontal axis, the waveguide-resonator gap is varied from 0.5 to $1.5 \mu \mathrm{m}$ with $0.3 \mu \mathrm{m}$ successive step size. Along the vertical direction, the width of GST varies from $0.5 \mu \mathrm{m}$ (bottom) to $20 \mu \mathrm{m}$ (top). (b) Comparison between resonances in the crystalline and amorphous states for different GST widths. The graphs show a relative shift of the central wavelength and the reduction of the Q-factor with broadening of the peaks. (c) ER obtained for different racetrack radii (R) as a function of GST width and state. The highlighted regions correspond to those highlighted in (b), and the lines correspond to the fits obtained using the analytical function for ER. (d) Concept of the dual-pulse programming technique; from left to right, an optical image of the device with a GST photonic memory cell, a magnified image of GST on top of the waveguide, and a schematic cross-section of the completed device [116]. (e) Experimental demonstration of multilevel photonic memory using multi-pulse PWM with 12 different levels in a single device showing the relative change in transmission $(\Delta \operatorname{Tr} / \operatorname{Tr} 0)$. This is an implementation of a switch for the photonic memory with each level accessed through the multiple identical pulse trains of 10 pulses with $\mathrm{p}=30 \mathrm{~ns}$ and $\mathrm{P}_{\text {peak }}=1.4 \mathrm{~mW}$. (f) Randomly accessing six levels of a single photonic memory. A multiple identical pulse train is used to reach different levels, with $\mathrm{N}=12, \mathrm{p}=20 \mathrm{~ns}$, and $\mathrm{P}_{\text {peak }}=1.6 \mathrm{~mW}$. Each level can be reached with the same pulse train at a determined width ( $\tau 0$ to $\tau 5$ ) from any previous level, where $\tau 0=10 \mathrm{~ns}, \tau 1=10.5 \mathrm{~ns}$, $\tau 2=11 \mathrm{~ns}, \tau 3=11.5 \mathrm{~ns}, \tau 4=12.5 \mathrm{~ns}$, and $\tau 5=15 \mathrm{~ns}$. The dotted and dashed lines denote the times when optical pulse trains are applied for amorphization and crystallization, respectively. ((a-c) reproduced with permission [111]; (d) reproduced under creative commons license from [116], (e,f), reproduced with permission [114]). 
For obvious reasons, the footprint of the micro-ring resonator-based device is comparatively large, and reducing it would enable a device with larger density. In such an attempt, the group of Pernice and Bhaskaran used a patch of GST on top of a straight $\mathrm{Si}_{3} \mathrm{~N}_{4}$ waveguide as a memory unit $[114,117]$. The device was able to achieve multi-level memory with 21 different states from a single unit of PCM achieved through partial crystallization of GST using pulse width modulation (PWM) on a low-power pump of $526 \mathrm{~mA}$. Figure 7d,e show the experimental demonstration of state transformations using PWM and random accessing of different levels of memory. As the need for frequent optoelectronic conversion is cumbersome, another study reported using integrated phase-change memory, which combines plasmonics, photonics, and electronics to achieve dual electrical and/or optical switching of multilevel states [115].

All of these devices consume relatively high power owing to the large absorption coefficient of GST. As reducing power consumption is the other major thrust of research on phase-change memories, GSST has been proposed as a unit of photonic integrated memory due to its lower absorption [25] and because electro-thermal switching is used for this device.

Following the successful demonstration of all photonic nonvolatile phase-change memory, some researchers resorted to electrically switched photonic memories for Si-PIC. As discussed earlier, electrical switching does offer some benefits compared to all photonic arrangements. It allows fabricating a micro-ring resonator using polycrystalline silicon as the memory element that is switched using joule heating generated using aluminum electrodes. The device consumes $0.476 \mathrm{pJ}$ and $0.316 \mathrm{pJ}$ for the write and read operations, respectively [118]. A similar technique used an ITO heater for heating and achieved switching in a silicon-based device using GST as the phase change material [119]. To further improve the quality of readout, plasmonics has also been used with electrically switched devices, which allows improving the switching speed and energy efficiency [120].

\section{In-Memory and Neuromorphic Computing Using PCM}

Neuromorphic computing is a paradigm that aims at emulating the way a brain computes, especially focusing on the property of the brain to carry out low-energy information processing, speedy processing, and complex and sophisticated tasks [121]. To mimic the brain, distributed computing topologies are generally used [122], which tend to emulate the behavior of a brain synapse. These structures, appropriately called "artificial synapses", have been used for machine learning. Most techniques for the implementation of machine learning rely on backpropagation $[123,124]$ as the method to achieve learning, except for a few [125]. Among those using backpropagation as the method of learning, Hebbian learning algorithms are the most popular [126,127].

Phase change material-based memristors have already been in research for a long time for the implementation of neuromorphic learning and in-memory computing [128,129]. The potential for using PCM-based photonic devices for neural networks including neuromorphic computing was understood right after the first report of PCM-based memory [130]. Since then, the neuromorphic potential of phase change materials has constantly been explored and developed (some of the major contribution in this regard have been outlined in Table 4). The first development in this regard was an all photonic synapse that implemented the Hebbian learning rule to achieve synaptic plasticity, made using multiple GST patches on a straight waveguide developed as a memory, already mentioned above $[95,117]$. In this device (schematic and scanning electron microscopic (SEM) pictures are shown in Figure $8 a, b)$, the synaptic weight is set by changing the number of optical pulses as the synaptic weight exponentially depends on the number of pulses. Using a pulse of $50 \mathrm{~ns}$ at $243 \mathrm{pJ}$, a $7 \%$ change in transmission was achieved corresponding to a synaptic weight of " 3 ". Subsequently, 100 pulses at $1 \mathrm{MHz}$ would allow the PCM to transition from " 3 " to " 1 ", while 1000 pulses would revert the state of the synapse to " 0 ". The research found that the synaptic weight is strictly dependent on the number of pulses applied. The reported 
device achieved 11 synaptic weights, which could be further improved to a truly analog system by improved pulse control, thereby improving the signal-to-noise ratio.

Table 4. Major contributions in neuromorphic/in-memory computational platforms.

\begin{tabular}{|c|c|c|c|c|c|c|}
\hline Year & PCM & Main Features & $\begin{array}{c}\text { All } \\
\text { Optical }\end{array}$ & Speed & Footprint & Power \\
\hline 2017 [117] & GST & $\begin{array}{c}\mathrm{Si}_{3} \mathrm{~N}_{4} \text {-based synapse, with } 21 \text { levels } \\
\text { on a single waveguide; Implemented } \\
\text { with multiple patches of GST on } \\
\text { straight waveguide }\end{array}$ & $\sqrt{ }$ & - & - & - \\
\hline 2019 [99] & GST & $\begin{array}{l}\text { Direct scalar multiplication with a } \\
\text { single integrated memory cell; } \\
\text { Matrix multiplication with multiple } \\
\text { PCM cells }\end{array}$ & $\sqrt{ }$ & $200 \mathrm{~ns}$ & - & $180 \mathrm{pJ}$ \\
\hline 2019 [18] & GST & $\begin{array}{c}\text { Synapses for supervised and } \\
\text { unsupervised self-learning; } \\
\text { Implemented with waveguides and } \\
\text { waveguide crossings with PCM on } \\
\text { top }\end{array}$ & $\sqrt{ }$ & $200 \mathrm{~ns}$ & - & $710 \mathrm{pJ}$ \\
\hline 2020 [100] & GST & $\begin{array}{l}512 \text { bit in-memory computing; } \\
\text { Saves } 16 \times 16 \text { grayscale image with } \\
\text { 2-bit resolution }\end{array}$ & $\sqrt{ }$ & - & $\begin{array}{c}1000 \times \\
2400 \mu \mathrm{m}^{2}\end{array}$ & $\begin{array}{l}110 \mathrm{pJ} \\
200 \mathrm{pJ} \\
230 \mathrm{pJ} \\
350 \mathrm{pJ}\end{array}$ \\
\hline 2021 [131] & GST & $\begin{array}{l}\text { Photonic convolutional neural } \\
\text { network with photonic computing } \\
\text { core through PMMC devices } \\
\text { Low-energy artificial synapse }\end{array}$ & $\sqrt{ }$ & $1 \mathrm{kHz}$ & - & 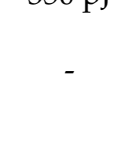 \\
\hline $2021[46]$ & $\mathrm{Sb}_{2} \mathrm{~S}_{3}$ and GST & $\begin{array}{c}\text { Nonlinear activation function } \\
\text { Accuracy }>90 \%\end{array}$ & $\sqrt{ }$ & $20 \mathrm{ps}$ & - & $0.1 \mu \mathrm{J}$ \\
\hline 2021 [132] & GST & $\begin{array}{l}\text { Integrated photonic tensor core for } \\
\text { parallel convolutional processing }\end{array}$ & $\sqrt{ }$ & $\begin{array}{c}10^{12} \mathrm{MAC} \\
\text { per } \\
\text { second }\end{array}$ & - & $\begin{array}{c}17 \\
\mathrm{fJ} / \mathrm{MAC}\end{array}$ \\
\hline
\end{tabular}

Creating a synapse on a single waveguide is very attractive from the point of view of reduced footprint, but the system is very difficult to scale; therefore, to create a network of synapses, a different approach is required. A silicon-based ring resonator with a GST patch is one such candidate that has been used for creating an all-optical synapse [133]. A similar synapse (schematically shown in Figure 8c) was also used to create an integrate-andfire neuron [23]. As any synaptic network is a dot-product engine, these ring resonators are connected in a network to essentially perform dot-product calculations in the form of multiplication of the input with the neuronal weight [134]. This neural network was trained, using a backpropagation algorithm, to recognize handwritten digits from the MNIST dataset [135], achieving $98.06 \%$ accuracy on testing. On the speed and energy efficiency front, the 'read' and 'write' actions take $500 \mathrm{ps}$ and $1.5 \mathrm{~ns}$ for $1 \mathrm{pJ}$ and $4 \mathrm{pJ}$, respectively, using pulses with a duration of 200 ps. This system was later further improved by better incorporation of wavelength division multiplexing [136] and behavioral modeling [137], which further improved energy and speed performance.

There is an inherent contradiction in the constant pursuit for decreasing the energy consumption of computing devices and having GST, which is a highly absorptive material, as the choice for PCM. Given the contradiction, it is only understandable that researchers are looking for alternative materials. In such an attempt, Volker produced an artificial synapse using GSST instead of GST [25]. For this synapse, they resorted to using an electrical switching method implemented using a tungsten contact instead of an optically switched technique. The neural network, made using of Mach-Zehnder interferometers (MZIs) with GSST on both arms, was trained and tested using MNIST [135] handwritten digits and was able to achieve a high level of accuracy. 

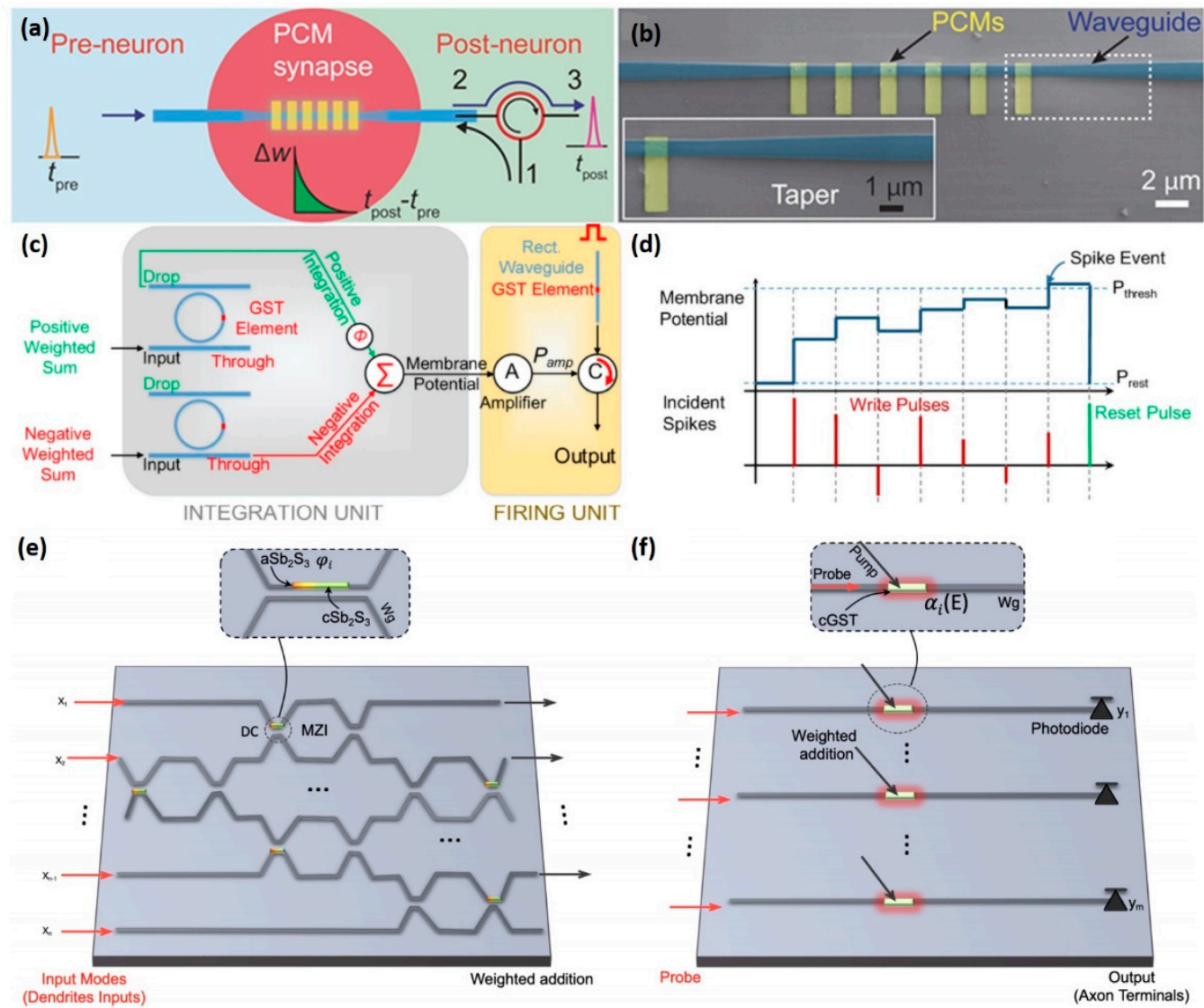

Figure 8. Various recent implementations for photonic neuromorphic computing. (a) Schematic of integrated photonic synapse functionally resembling a biological neural synapse where a waveguide is covered with islands of PCM, forming a connection between the pre-neuron and post-neuron parts of the circuit. The post-neuron section contains a circulator (red circle) used to route the output from the synapse to the postsynaptic region and weight (control signals) from port 1 to synapse. (b) SEM image of the photonic synapse presented in (a). (c) Schematic of a bipolar integrate-and-fire neuron implemented using a GST patch straddling on ring resonators. (d) Timing diagram of the bipolar integrate-and-fire neuron presented in (c) showing integration of membrane potential under various incident pulses. (e) An artificial photonic neuron based on PCM. The weighting mechanism and summation rely on a cascade of $\mathrm{Sb}_{2} \mathrm{~S}_{3}-\mathrm{SiN}$ hybrid photonic switches which perform operations equivalent to that of a field-programmable gate array (FPGA). Upon placing PCM on one side of the directional coupler (DC), light is partially configured to the cross state following the material being written (crystalline to amorphous). (f) Nonlinear activation function (NLAF) made with GST patches on a silicon waveguide. Nonlinear variations in refractive index are sensed with TM polarized light. ((a,b) reproduced under creative commons license [95]; $(\mathbf{c}, \mathbf{d})$ reproduced under creative commons license [23]; (e,f) reproduced under creative commons license from article in arXiv [46]).

Scaling the neural network further, [25] recently presented a synapse, graphical processing unit, and a tensor processing unit that perform in-memory calculations through the network of coupler-based latch circuit using $\mathrm{Si}_{3} \mathrm{~N}_{4}$ with $\mathrm{Sb}_{2} \mathrm{~S}_{3}$, as well as GST as the PCM [46]. The network (shown in Figure 8e,f) performs at the maximum data rate of $100 \mathrm{GHz}$ and consumes $0.1 \mathrm{uJ}$ of energy. In another work, the tensor processing unit was implemented using GST on a network of ring resonators [137,138]. The implementation of ring resonators helps in reducing the power consumption as the GST is not directly in contact with the propagating waves. They implement parallel processing for convolutional operation showing a variety of machine learning tasks at 2 tera-MAC operations per second with a modulation speed of more than $13 \mathrm{GHz}$ consuming $17 \mathrm{fJ}$ per MAC. This is thus far the fastest implementation of an all-photonic in-memory computational network. The speed, according to the study, can be further improved by expanding the size of the network to increase the level of parallelization. 


\section{Phase Change Modulators and Switches}

Metasurfaces that are artificially micro/nanostructured in a certain way to perform the function of modulators and switches are important PCM-based integrated photonic devices. Such devices generally contain microstructures that partially or fully contain phase change materials in them. The applications of such metasurfaces in producing switches [87,139-141], transmission tuners [91], and modulators [19,142-145] are ubiquitous, which are generally implemented using either Mach-Zehnder interferometers (MZI) or ring resonators [146]. While the major contributions in PCM-based photonic switches and modulators have been outlined in Table 5, the important features of these switches and modulators as per Abdollahramezani are their low power, high contrast, and fast speed [146]. To achieve these features, other than the design parameters, the device is also dependent upon the fabrication processes adopted. As no method is perfect and each method has its own advantages and disadvantages [147].

Table 5. Major contributions in PCM-based photonic switches and modulators.

\begin{tabular}{|c|c|c|c|c|c|c|}
\hline Year & PCM & Main Features & $\begin{array}{c}\text { All } \\
\text { Optical }\end{array}$ & Speed & Footprint & $\begin{array}{l}\text { Insertion } \\
\text { Loss }\end{array}$ \\
\hline 2010 [142] & $\mathrm{VO}_{2}$ & $\begin{array}{l}\text { Ring } \\
\text { resonator-based } \\
\text { modulator }^{1}\end{array}$ & $\sqrt{ }$ & - & $2 \mu \mathrm{m}, 5 \mu \mathrm{m}$ & $2 \mathrm{~dB}$ \\
\hline 2012 [143] & $\mathrm{VO}_{2}$ & $\begin{array}{l}\text { Ring } \\
\text { resonator-based } \\
\text { modulator }^{2}\end{array}$ & $\sqrt{ }$ & - & $0.28 \mu \mathrm{m}^{2}$ & - \\
\hline 2012 [148] & GST & $\begin{array}{c}2 \times 2 \text { MZI-based } \\
\text { switch }^{2}\end{array}$ & $\sqrt{ }$ & - & $\begin{array}{c}93 \times \\
1.7 \mu \mathrm{m}^{2}\end{array}$ & $0.5 \mathrm{~dB}$ \\
\hline 2012 [149] & $\mathrm{VO}_{2}$ & $\begin{array}{c}2 \times 2 \text { plasmonic } \\
\text { switch }^{2}\end{array}$ & $x$ & $10 \mathrm{~s} \mathrm{kHz}$ & $5 \mu \mathrm{m}$ & $1.5 \mathrm{~dB}$ \\
\hline 2013 [150] & GST & $\begin{array}{c}\text { Ring } \\
\text { resonator-based } \\
\text { switch }^{2}\end{array}$ & $\sqrt{ }$ & - & - & $2.5 \mathrm{~dB}$ \\
\hline 2014 [151] & $\mathrm{VO}_{2}$ & $\begin{array}{l}\text { Plasmonic } \\
\text { modulator }\end{array}$ & $\times$ & - & $9.47 \mu \mathrm{m}$ & $4.5 \mathrm{~dB}$ \\
\hline 2015 [152] & $\mathrm{VO}_{2}$ & Switch $^{2}$ & $\times$ & $500 \mathrm{~ns}$ & $\begin{array}{c}0.3 \times \\
0.5 \mu \mathrm{m}^{2}\end{array}$ & $<3.6 \mathrm{~dB}$ \\
\hline 2017 [153] & $\mathrm{VO}_{2}$ & Modulator ${ }^{2}$ & $x$ & $3 \mathrm{~ns}$ & $6 \mu \mathrm{m}$ & $0.3 \mathrm{~dB}$ \\
\hline 2017 [89] & GST & Switch ${ }^{3}$ & $x$ & - & $3 \mu \mathrm{m}$ & $2 \mathrm{~dB}$ \\
\hline 2018 [154] & $\mathrm{VO}_{2}$ & $\begin{array}{l}\text { Plasmonic } \\
\text { modulators }\end{array}$ & $\times$ & $1 \mathrm{GHz}$ & $2 \mu \mathrm{m}^{2}$ & $1.4 \mathrm{~dB} / \mu \mathrm{m}$ \\
\hline 2018 [14] & GST & Modulator $^{4}$ & $\times$ & - & $0.2 \mu \mathrm{m}^{2}$ & $<2 \mathrm{~dB}$ \\
\hline 2019 [155] & GSST & $\begin{array}{l}\text { Switch }^{2} \\
\text { Plasmonic }\end{array}$ & $\sqrt{ }$ & - & $5 \mu \mathrm{m}$ & $0.135 \mathrm{~dB}$ \\
\hline 2019 [156] & GST & $\begin{array}{l}\text { modulator for } \\
\text { MIM device }^{2}\end{array}$ & $\sqrt{ }$ & $500 \mathrm{ps}$ & $120 \mathrm{~nm}$ & $3.6 \mathrm{~dB}$ \\
\hline 2020 [98] & GST & $\begin{array}{l}\text { Switch with } \\
\text { PCM in a slot }{ }^{2}\end{array}$ & $\times$ & - & $0.014 \mu \mathrm{m}^{2}$ & $<4 \mathrm{~dB}$ \\
\hline 2020 [157] & GST & $\begin{array}{c}\text { MZI-based }^{5} \\
\text { Ring }\end{array}$ & $x$ & $\approx \mathrm{ns}$ & $5 \mu \mathrm{m}^{2}$ & $4 \mathrm{~dB}$ \\
\hline 2021 [158] & $\mathrm{Sb}_{2} \mathrm{Se}_{3}$ & $\begin{array}{l}\text { resonator-based } \\
\text { modulator }^{2}\end{array}$ & $\sqrt{ }$ & $800 \mathrm{~ns}$ & $11 \mu \mathrm{m}^{2}$ & $0.45 \mathrm{~dB}$ \\
\hline
\end{tabular}

${ }^{1}$ Operating wavelength: $1250-1450 \mathrm{~nm} .{ }^{2}$ Operating wavelength: $1550 \mathrm{~nm} .{ }^{3}$ Operating wavelength: $1525-1625 \mathrm{~nm} .{ }^{4}$ Operating wavelength: $1530-1650 \mathrm{~nm} .{ }^{5}$ Operating wavelength: $1260-1320 \mathrm{~nm}$.

\section{1. $\mathrm{VO}_{2}$ Metasurfaces}

Vanadium dioxide-based on-chip modulators have been around for a bit longer than GST-based devices [142,144]. In these devices (shown in Figure 9), a ring resonator with a small patch of $\mathrm{VO}_{2}$ on the ring is fabricated. The change in temperature causes a change in the phase of $\mathrm{VO}_{2}$, leading to a change in the resonant frequency. An extended such 
device would yield modulation of $16 \mathrm{~dB}$, which is comparable with MZI. In this device, the temperature is changed using substrate heating. In a subsequent study, the phase change was caused externally by a $532 \mathrm{~nm}$ wavelength pump laser, leading to modulation of $10 \mathrm{~dB}$ in a ring resonator with a radius of $1.5 \mu \mathrm{m}$ [143]. The experimental setup and the result of modulation achieved with this arrangement are shown in Figure $9 \mathrm{c}, \mathrm{d}$, respectively. On the other hand, a more recent study reported a modulator with an extinction ratio of $25 \mathrm{~dB}$ and a low insertion loss of $1.4 \mathrm{~dB}$. This was achieved by using a ring resonator with a $\mathrm{VO}_{2}$ patch, which was thermally tuned through lateral micro-heaters placed beside the waveguide [159].

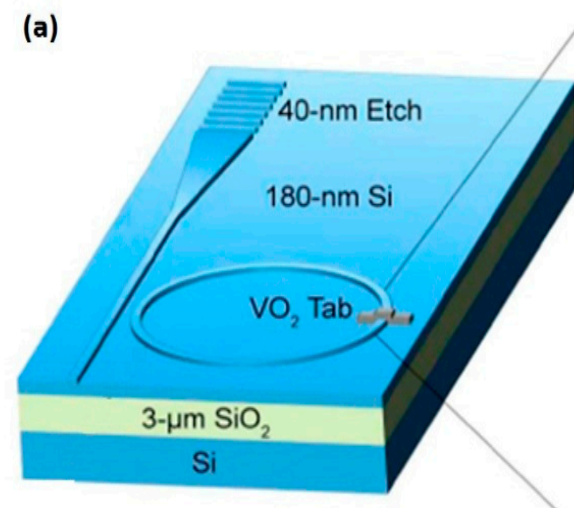

(b)

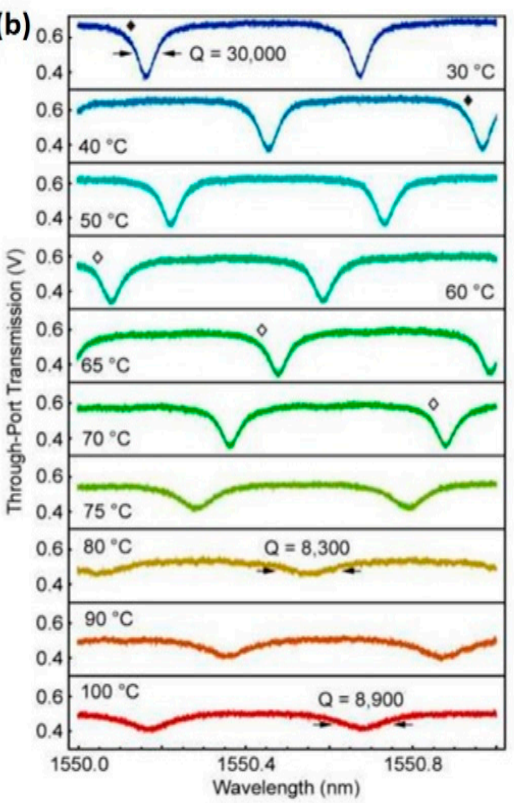

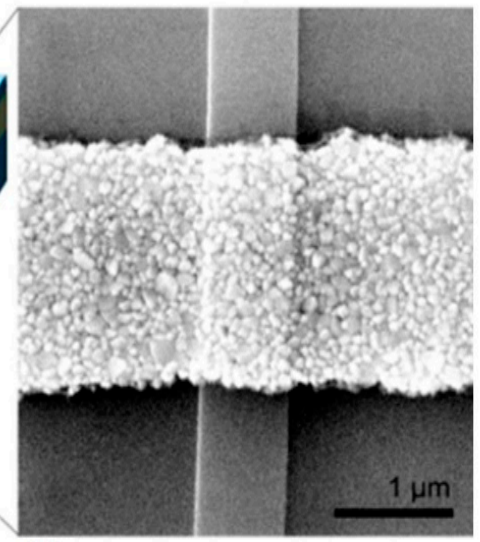

(c)

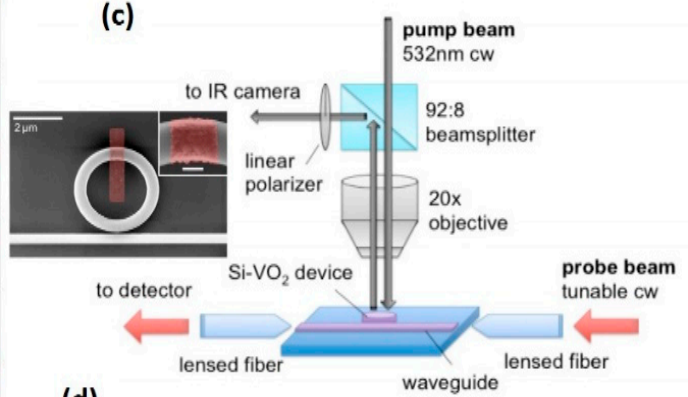

(d)

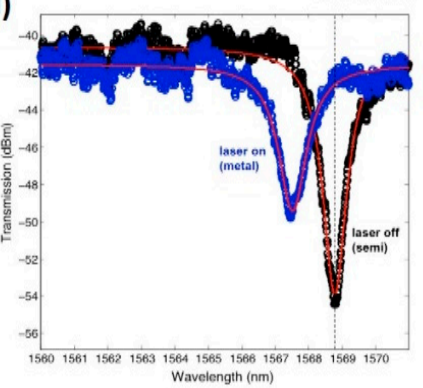

Figure 9. Photonic modulators and switches using $\mathrm{VO}_{2}$ as the PCM. (a) Schematic of $\mathrm{VO}_{2}$ modulator consisting of a grating coupler, a silicon bus waveguide, and a silicon ring resonator covered with a strip of $\mathrm{VO}_{2}$. The SEM image of the $\mathrm{VO}_{2}$ patch straddling the waveguide is shown on the right. (b) Transmission spectra of the through port at increasing temperatures for the schematic presented in (a). The modes of the same azimuthal order are indicated with diamond-shaped markers. These markers show a temperature-dependent red-shift. (c) Schematic of the measurement setup of a $\mathrm{VO}_{2}$-based optical modulator. The SEM image of the modulator is shown in the inset. (d) Optical transmission from the setup given in (c) before and after the trigger. The spectra show a blue-shift upon exposure to the trigger. ((a,b) reproduced under creative commons license [142]; (c,d) reproduced under creative commons license [143]).

One bottleneck in the performance of $\mathrm{VO}_{2}$ modulators is that the transverse electric (TE) polarized mode interacts weakly with them compared to the transverse magnetic 
(TM) mode. Some solutions have been proposed to avoid this problem such as using a vertical slot coupler with $\mathrm{VO}_{2}$ active layer [151], delocalization of mode in a small waveguide [149], and using a modulator coupled with a compact mode converter to improve the modulation [153]. These solutions try to optimize the trade-off between insertion loss and extinction ratio while also keeping the device footprint compact. In one such proposal, a layer of silver was added between the vanadium dioxide layer and the silicon layer. This unique hybrid plasmonic solution could reduce the insertion loss while maintaining a high extinction ratio [154].

As $\mathrm{VO}_{2}$ is transitioned to a metallic state which is lossy for electromagnetic waves upon increasing the temperature, this feature opens up the possibility of using $\mathrm{VO}_{2}$ as a switch in photonic circuits. This was shown by the work of Poon [152]. In this design, to make an effective switch of both TE and TM modes, a narrower silicon waveguide was used, and then it was clad with a $\mathrm{VO}_{2}$ patch on all three sides. This increased the interaction of both TE and TM modes, helping in effective switching [152]. The device reported an extinction ratio of $12 \mathrm{~dB}$ and insertion loss of $5 \mathrm{~dB}$. The device is electrically switched, having turn-off times of $350 \mathrm{~ns}$ and $750 \mathrm{~ns}$, while not relying on hybrid plasmonic design helps to simplify the fabrication process. This design can be improved by using a twoterminal configuration, which helps in applying a large electric field without suppressing the leakage current, thereby drastically reducing the switch-on time to $2 \mathrm{~ns}$ [141].

Some interesting studies have been conducted to study the transition dynamics for improvement of switching time of electrically switched $\mathrm{VO}_{2}$-based devices $[160,161]$ and optically switched $\mathrm{VO}_{2}$-based devices [162,163]. For electrically switched devices, the switching time dominated by a spatially percolated metallic phase [161] is improved by increasing the peak pulse [160]. Similarly, in the case of optically switched devices, the switching time can range from a few nanoseconds to microseconds depending on the incident power [162], and a faster relaxation to insulating state can be achieved by using doped $\mathrm{TiO}_{2}: \mathrm{Nb}$ substrate [163].

\subsection{Chalcogenide Modulators and Switches}

$\mathrm{VO}_{2}$-based devices are good for volatile applications requiring reasonably high switching speed, but the states are volatile. On the other hand, as seen earlier, chalcogenide devices show nonvolatile switching, making them useful for nonvolatile applications but at the expense of speed, a bottleneck that has been broken with recent research. Moreover, as maintaining the state in a volatile switch may require a constant supply of energy, this may not be a very energy-efficient method of switching. The advantage of only supplying energy when switching is needed instead of a constant supply of energy for maintenance of the state was highlighted in the work of $\mathrm{Xu}$ in reports on GST-based electro-optical modulators [14,148]. In the work by the group of Xu on GST [14], a modulator for C-band was presented that is electrically switched, has a footprint of $0.2 \mu \mathrm{m}^{2}$, has an extinction ratio larger than $5.4 \mathrm{~dB}$ for a switch, and consumes sub-nJ energy per cycle for each switch. This is achieved by a copper-clad $30 \mathrm{~nm}$ patch of GST on top of the silicon waveguide. This combination performs better than the various other recipes, such as the silicon-ITO-GST waveguide (shown in Figure 10a) [89] using an ITO heater instead of a copper heater on a straight waveguide, the abovementioned $\mathrm{Si}-\mathrm{VO}_{2}$ ring resonator-based modulator [142], Si-GST micro-ring [150], and silicon reverse-biased ring made using oppositely poled silicon and modulated through electrical means. 

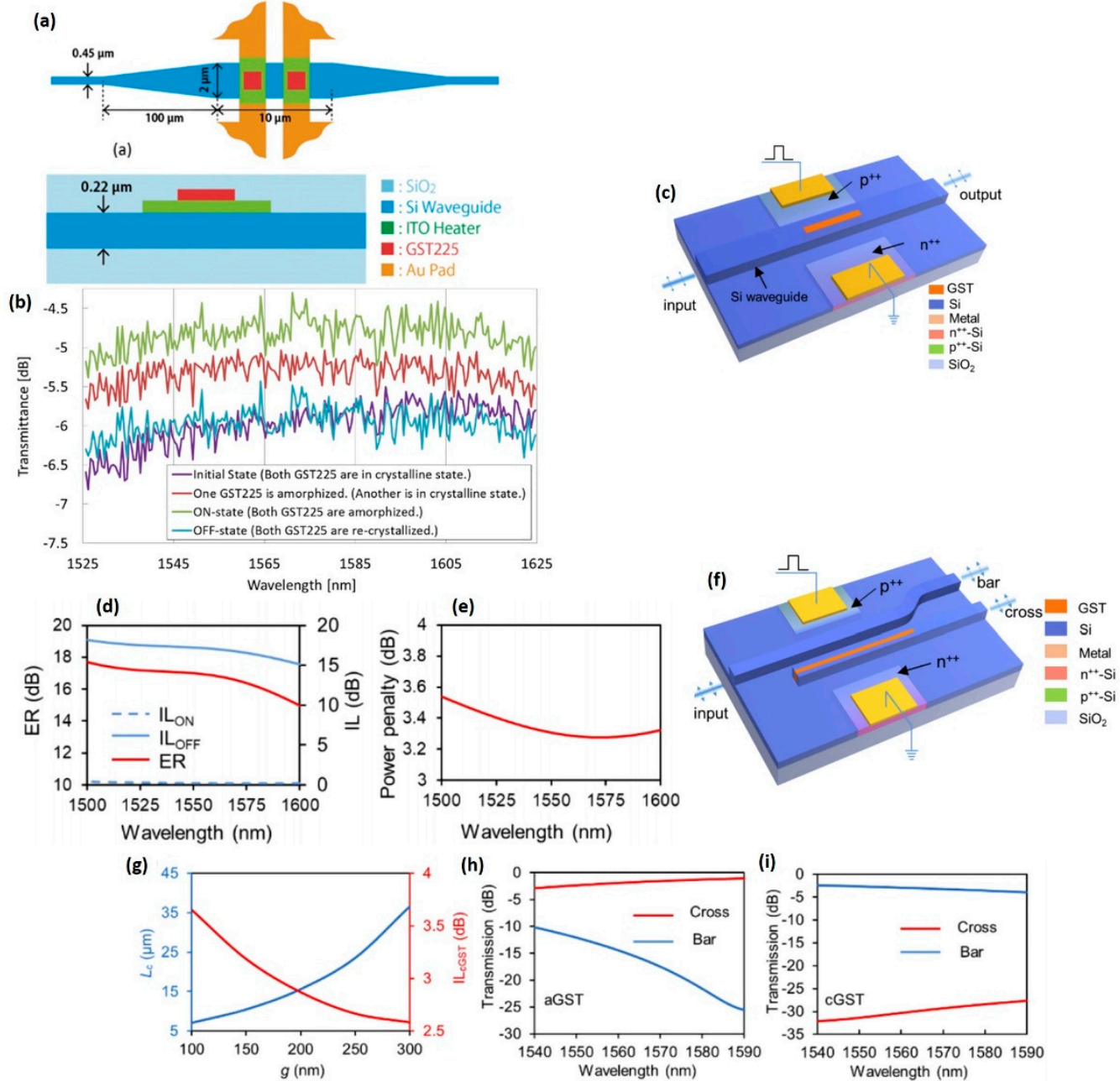
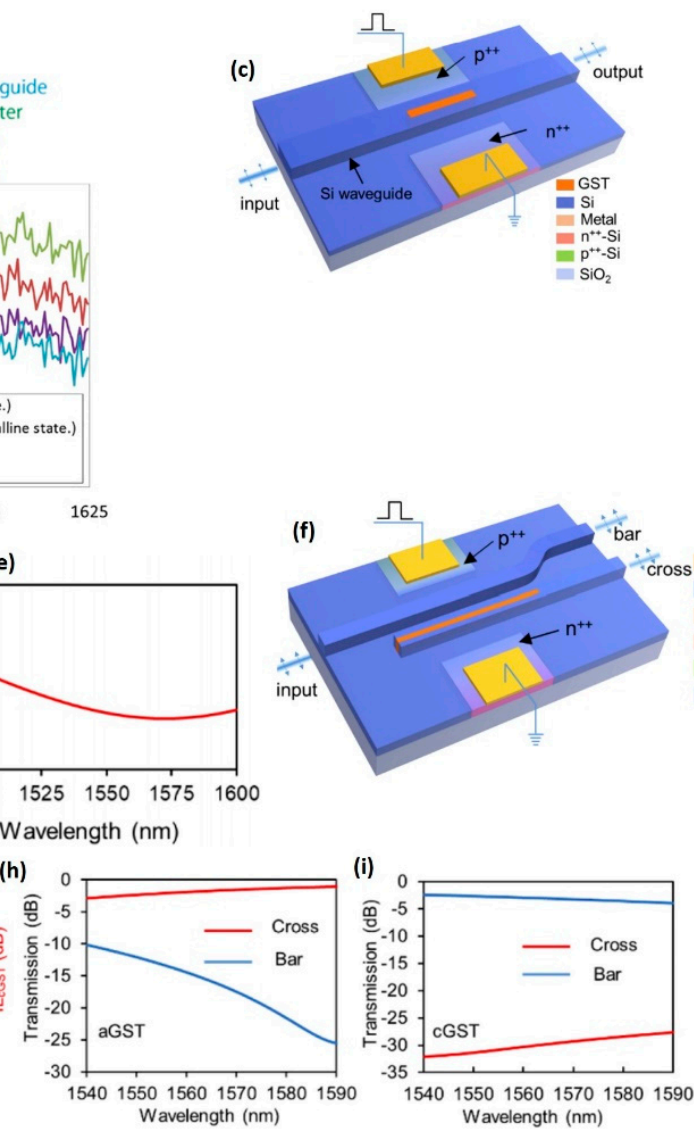

Figure 10. Switches and modulators based on chalcogenide PCM. (a) Schematic top view and cross-section of GST-based optical switch using current-controlled ITO heaters. (b) Optical transmission spectra of GST-based optical switch shown in (a). The spectra contain the transmission from the switch under different configurations. (c) Schematic of the perspective view of the modulator with GST in a slot. (d) On/off extinction ratio (ER) and the insertion losses of the EA modulator presented in (c). (e) Power penalty of the EA modulator shown in (c) as a function of wavelength along the propagation length. (f) Schematic of the perspective view of the $1 \times 2$ DC switch. GST is implanted in a slot instead of straddling the waveguide. (g) Coupling length of the maximum transmission in the amorphous state and the insertion loss in the crystalline state as a function of $\mathrm{g}$ (the gap size between the waveguides). Transmission spectra at the cross and bar ports for (h) amorphous GST and (i) crystalline GST for the switch presented in (f). ((a,b) reproduced under creative commons license [89]; (c-i) reproduced under creative commons license [98]).

As silicon suffers from large two-photon absorptions in the near-infrared range, it is considered useful to use silicon nitride instead of silicon for near-infrared devices. For this reason, GST on silicon nitride-based modulators have been a popular subject of research $[139,163,164]$.

However, in general, silicon remains the most frequently used substrate material for on-chip modulation and switching applications based on PCMs. Using GST encapsulated by ITO for electrical switching purposes was also demonstrated by Zhang [7]. In this work, a GST patch was placed on top of a silicon MMI, and switching GST from amorphous to crystalline resulted in transmission contrast of $20 \mathrm{~dB}$ over the wavelength range of $1500 \mathrm{~nm}$ to $1600 \mathrm{~nm}$. This was achieved using a $20 \mathrm{~ns}$ write pulse of $10.4 \mathrm{~nJ}$ resulting in GST amorphization, and a $100 \mathrm{~ns}$ erase pulse of $9 \mathrm{~nJ}$ resulting crystallization of the GST patch. They additionally showed partial crystallization of the GST leading to multiple possible states of crystallization. In separate work, the group also demonstrated the feasibility 
of using GST-based electrical switching encapsulated by ITO for multiple applications including wavelength division multiplexing and filtering [91]. As also discussed earlier, the interaction region in the straddling PCM is less than an in-line PCM. Placing the GST in line improves the interaction of optical wave and GST, leading to improved switching performance, such as a higher extinction ratio of $33.1 \mathrm{~dB}$ and low insertion loss of $0.48 \mathrm{~dB}$ for an optical wavelength of $1550 \mathrm{~nm}$ [87].

The arrangement of in-line GST for increased interaction has also recently been used for metal-insulator-metal (MIM)-type plasmonic waveguide switches and modulators, where GST is externally switched through pump light [156]. This work investigated three MIM structures such as an end-coupled rectangular resonator, a side-coupled stub resonator, and two mutually coupled resonators. The end-coupled rectangular resonator, the side-coupled stub resonator, and two mutually coupled resonators showed insertion loss of $3.6 \mathrm{~dB}$ for fully amorphous and $13.8 \mathrm{~dB}$ for crystalline, $16.8 \mathrm{~dB}$ for fully amorphous and $2.4 \mathrm{~dB}$ for fully crystalline, and $2.6 \mathrm{~dB}$ for fully amorphous and $17 \mathrm{~dB}$ for fully crystalline states, respectively. The modulation depth reported for these three structures was $13.8 \mathrm{~dB}$, $14.4 \mathrm{~dB}$, and $14.4 \mathrm{~dB}$, respectively, with a switching speed of $500 \mathrm{ps}$. This modulation depth is intermediate among that achieved in similar work such as Haddadpour's magnetooptical switch [164] and Piao's Fano transparency controlled switching [165].

Another method to produce a sort of hybrid between an in-line and a matched PCM layer was introduced by Liang, whereby a $10 \mathrm{~nm}$ GST layer was sandwiched between two doped silicon layers in an arrangement also called "anti-slot" [166]. The author simulated electrically switched switches and modulators for an operating wavelength of $2.1 \mu \mathrm{m}$ and was able to numerically validate an MZI with a device length of $38 \mu \mathrm{m}$ and insertion loss of $-16 \mathrm{~dB}$, while achieving a state transition time of less than $100 \mathrm{~ns}$. In subsequent work, the group also numerically demonstrated modulation of $2.1 \mu \mathrm{m}$ wavelength using $2 \times 2$ devices along with one- and two-island waveguides between them [167].

Power consumption in GST-based systems is an important issue, which has led to some researchers exploring other platforms such as $\mathrm{Sb}_{2} \mathrm{~S}_{3}[45,47], \mathrm{Sb}_{2} \mathrm{Se}_{3}$ [158], and GSST [155] for switching and modulation applications. Given that these are newer platforms, there has not been a lot of progress in this direction, but they are promising. The $\mathrm{Sb}_{2} \mathrm{~S}_{3}$ - and GSSTbased switches reported lower insertion losses of $0.48 \mathrm{~dB}$ and $0.135 \mathrm{~dB}[47,155]$, device lengths of $8 \mu \mathrm{m}$ and $5 \mu \mathrm{m}$, and extinction ratios of $30 \mathrm{~dB}$ and $20 \mathrm{~dB}$, respectively. $\mathrm{Sb}_{2} \mathrm{Se}_{3}$ based modulators using ring resonators as the basic structure demonstrated an insertion loss of $0.45 \mathrm{~dB}$ and switching energy of $185 \mathrm{~nJ}$ for an electrically switched device [158].

The low-loss nature of these platforms has also encouraged nonconventional applications for PCMs such as MMI switches [45]. On the other hand, GST-based novel designs have also been proposed, which tend to address the power consumption issue of GSTbased devices, producing ultra-low-power nonvolatile switches, by using a GST-filled slot instead of using a GST patch for the whole width of the waveguide. The proposed design (shown in Figure 10c,f) is electrically switched and can reach an extinction ratio of $17 \mathrm{~dB}$ at $1550 \mathrm{~nm}$ with a high energy efficiency of $64 \mathrm{aJ} / \mathrm{nm}^{3}$ for the crystallization and amorphization transitions [98]. However, these are simulation-based results, and whether an actual GST-based device is able to give such a performance in an in-line setting remains to be seen.

\section{Discussion and Outlook}

Phase change materials are unique in that they drastically change their electrical and optical properties upon the introduction of an external stimulus. Even though these materials have been around for some decades, they have come only recently into focus for designers of on-chip devices. Since the early devices in the early 2010s, a lot of progress has been made in the direction of on-chip PCM-based devices. While most of the progress has been directed toward application in memory devices and neuromorphic computational platforms, a lot of progress has also been made in applications such as switches and modulators. Most of the major contributions in the areas of memory and neuromorphic 
computing are tabulated in Tables 3 and 4, while most of the major contributions in switches and modulators are tabulated in Table 5.

GST has by far been the most successful phase change material in terms of acceptability among the research community. This has led to the use of GST in every possible conventional application of PCMs including memory devices, neuromorphic computational platforms, photonic switches, and modulators, which have been implemented using electrical switching, as well as optical switching. While optical switching methods are difficult to scale at present due to the difficulties in the routing of control signals and data signals, electrical switching methods overcome these issues due to inherent differentiation in the routing circuits for control and data signals.

The increased interest in energy conservation through energy efficiency has led to the exploration of material platforms for PCMs that have a low loss. Among these low-loss material platforms, $\mathrm{Sb}_{2} \mathrm{Se}_{3}, \mathrm{Sb}_{2} \mathrm{~S}_{3}$, and GSST are the most prominent materials. GSST is a newer platform while $\mathrm{Sb}_{2} \mathrm{Se}_{3}$ and $\mathrm{Sb}_{2} \mathrm{~S}_{3}$ are old but not forgotten materials. This exploration reintroduced these low-loss chalcogenide phase change materials. Although these low-loss materials improve the energy performance of these applications, they also enhance the horizon of possible applications with the induction of devices such as MMIs and beam splitters into the possible applications of on-chip PCMs. This horizon is expected to further increase in the near future with the possible on-chip demonstration of various computational and beam steering platforms already available for free-space applications but difficult to implement on chip due to the losses of GST. Such applications can be implemented on the on-chip platforms using such low-loss PCMs.

After these chalcogenide materials, the most prevalent material is $\mathrm{VO}_{2}$. Although, in terms of refractive index contrast, it is comparable with GST which could potentially make it a rival technology, its states are volatile and can only be maintained through a continuous supply of energy making them only suitable for volatile applications. Due to this property of $\mathrm{VO}_{2}$, its performance does not fare well with the contemporary energy conservation and energy efficiency frameworks. Earlier, it had the advantage of faster switching over GST, but that advantage is also slipping due to new and improved switching methods for chalcogenide PCMs, which means that, although chalcogenide PCMs need activation of control circuitry at each switch between crystalline and amorphous phase, they are still able to achieve faster switching compared with $\mathrm{VO}_{2}$ devices. Nevertheless, $\mathrm{VO}_{2}$ has still found some applications in switching and modulation, where the performance of $\mathrm{VO}_{2}$-based devices is not better than its chalcogenide-based counterparts.

At present, the research in nonconventional material platforms such as silicon and organic materials is seriously lacking. Although silicon has been demonstratively used in a few applications through poling and doping to achieve contrasting phases, the contrast is small, restricting its possible use in actual devices. On the other hand, organic PCMs have not been used at all in photonic devices. However, given their increasingly successful use in resistance-based applications, it is only a matter of time before they also find their way into on-chip refractive index-based devices. The literature reports both volatile and nonvolatile organic PCMs with demonstrable application in resistance-based memristive memory devices. The volatile category includes materials such as PNIPAMs and PEDOTs, while the nonvolatile category includes materials made from aromatic compounds. While the change of phase in these organic PCMs leads to a change in their resistance, due to the lack of research in this area, it remains to be seen whether the phase change also corroborates with a change in the refractive index. Only those materials which show considerable refractive index contrast will be most useful for photonic applications.

The phase change materials and, thus, the devices based on them are deemed essential for next-generation low-power memory devices and neuromorphic computational platforms. The introduction of low-loss materials will be very helpful in the diversification of possible PCM applications in the future. Such diversification is extremely essential to realize one day a fully functional all-optical computing device of conventional and neuromorphic kind. The current developments in this field are healthy but at a very early 
stage for the realization of practical devices, implying that there still is a long way to go. The future will hold many more interesting applications of PCMs among those discussed above or even newer material platforms with more interesting properties aligning with the needs of specific applications.

Author Contributions: Conceptualization, M.S.N. and L.Z.; writing-original draft preparation, M.S.N.; writing - review and editing, M.S.N., X.Y., L.L., J.C. and L.Z.; supervision, L.Z.; funding acquisition, L.Z. All authors read and agreed to the published version of the manuscript.

Funding: This research was funded by the National Key Research and Development Program (2019YFB2203200, 2018YFB2201702, 2019YFB1802903), the National Natural Science Foundation of China (NSFC) (62090052, 6207030193), and the Shanghai Municipal Science and Technology Major Project (2017SHZDZX03).

Institutional Review Board Statement: Not applicable.

Informed Consent Statement: Not applicable.

Data Availability Statement: Not applicable.

Conflicts of Interest: The authors declare no conflict of interest.

\section{References}

1. Balanis, C.A. Antenna Theory Analysis and Design. Pdf, 2nd ed.; Wiley Sons Inc.: New York, NY, USA, 1997.

2. Tien, P.K. Light Waves in Thin Films and Integrated Optics. Appl. Opt. 1971, 10, 2395-2413. [CrossRef]

3. Capolino, F. Theory and Phenomena of Metamaterials; Capolino, F., Ed.; CRC Press: Boca Raton, FL, USA, 2017; Volume 8, ISBN 9781315219370.

4. Siegrist, T.; Merkelbach, P.; Wuttig, M. Phase Change Materials: Challenges on the Path to a Universal Storage Device. Annu. Rev. Condens. Matter Phys. 2012, 3, 215-237. [CrossRef]

5. Wang, L.; Tu, L.; Wen, J. Application of phase-change materials in memory taxonomy. Sci. Technol. Adv. Mater. 2017, 18, 406-429. [CrossRef] [PubMed]

6. Singh, M.; Raghuwanshi, S.K.; Srinivas, T. Nanophotonic On-Chip hybrid plasmonic Electro-Optic modulator with phase change materials. Phys. Lett. Sect. A Gen. At. Solid State Phys. 2019, 383, 3196-3199. [CrossRef]

7. Zhang, H.; Zhou, L.; Lu, L.; Xu, J.; Wang, N.; Hu, H.; Rahman, B.M.A.A.; Zhou, Z.; Chen, J. Miniature Multilevel Optical Memristive Switch Using Phase Change Material. ACS Photonics 2019, 6, 2205-2212. [CrossRef]

8. Wang, N.; Zhang, H.; Zhou, L.; Lu, L.; Chen, J.; Rahman, B.M.A. Design of ultra-compact optical memristive switches with GST as the active material. Micromachines 2019, 10, 453. [CrossRef]

9. Ruiz de Galarreta, C.; Carrillo, S.G.C.; Au, Y.-Y.; Gemo, E.; Trimby, L.; Shields, J.; Humphreys, E.; Faneca, J.; Cai, L.; Baldycheva, A.; et al. Tunable optical metasurfaces enabled by chalcogenide Phase-Change materials: From the visible to the THz. J. Opt. 2020, 22, 114001. [CrossRef]

10. Pernice, W.H.P.; Bhaskaran, H. Photonic non-volatile memories using phase change materials. Appl. Phys. Lett. 2012, 101, 171101. [CrossRef]

11. Wang, J.; Wang, L.; Liu, J. Overview of Phase-Change Materials Based Photonic Devices. IEEE Access 2020, 8, 121211-121245. [CrossRef]

12. Feldmann, J.; Stegmaier, M.; Gruhler, N.; Ríos, C.; Bhaskaran, H.; Wright, C.D.; Pernice, W.H.P.P. Calculating with light using a chip-Scale all-Optical abacus. Nat. Commun. 2017, 8, 1256. [CrossRef]

13. Shadmani, A.; Miri, M. Design and Simulation of Dual Polarization GST-On-Silicon Nitride Optical Modulator. In Proceedings of the 2019 27th Iranian Conference on Electrical Engineering (ICEE), Yazd, Iran, 30 April-2 May 2019.

14. Yu, Z.; Zheng, J.; Xu, P.; Zhang, W.; Wu, Y. Ultracompact Electro-Optical Modulator-Based Ge 2 Sb 2 Te 5 on Silicon. IEEE Photonics Technol. Lett. 2018, 30, 250-253. [CrossRef]

15. Ghosh, R.R.; Bhardwaj, P.; Dhawan, A. Numerical modeling of integrated electro-Optic modulators based on mode-gap shifting in photonic crystal slab waveguides containing a phase change material. J. Opt. Soc. Am. B 2020, 37, 2287. [CrossRef]

16. Wei, Y.; Zhang, M.; Dai, D. Multichannel mode-selective silicon photonic add/drop multiplexer with phase change material. J. Opt. Soc. Am. B 2020, 37, 3341. [CrossRef]

17. Wang, L.; Lu, S.R.; Wen, J. Recent Advances on Neuromorphic Systems Using Phase-Change Materials. Nanoscale Res. Lett. 2017, 12. [CrossRef]

18. Feldmann, J.; Youngblood, N.; Wright, C.D.; Bhaskaran, H.; Pernice, W.H.P.P. All-Optical spiking neurosynaptic networks with self-learning capabilities. Nature 2019, 569, 208-214. [CrossRef] [PubMed]

19. Miller, K.J.; Haglund, R.F.; Weiss, S.M. Optical phase change materials in integrated silicon photonic devices: Review. Opt. Mater. Express 2018, 8, 2415. [CrossRef] 
20. Yang, Z.; Ramanathan, S. Breakthroughs in photonics 2014: Phase change materials for photonics. IEEE Photonics J. 2015,7 , 1-5. [CrossRef]

21. Ding, F.; Yang, Y.; Bozhevolnyi, S.I. Dynamic Metasurfaces Using Phase-Change Chalcogenides. Adv. Opt. Mater. 2019, 7, 1801709. [CrossRef]

22. Guo, P.; Sarangan, A.M.; Agha, I. A Review of Germanium-Antimony-Telluride Phase Change Materials for Non-Volatile Memories and Optical Modulators. Appl. Sci. 2019, 9, 530. [CrossRef]

23. Chakraborty, I.; Saha, G.; Sengupta, A.; Roy, K. Toward Fast Neural Computing using All-Photonic Phase Change Spiking Neurons. Sci. Rep. 2018, 8, 12980. [CrossRef]

24. Delaney, M.; Zeimpekis, I.; Lawson, D.; Hewak, D.W.; Muskens, O.L. A New Family of Ultralow Loss Reversible Phase-Change Materials for Photonic Integrated Circuits: $\mathrm{Sb}_{2} \mathrm{~S}_{3}$ and $\mathrm{Sb}_{2} \mathrm{Se}_{3}$. Adv. Funct. Mater. 2020, 30, 2002447. [CrossRef]

25. Miscuglio, M.; Meng, J.; Mehrabian, A.; Sorger, V.; Yesiliurt, O.; Prokopeva, L.; Kildishev, A.; Zhang, Y.; Hu, J. Artificial Synapse with Mnemonic Functionality using GSST-based Photonic Integrated Memory. Appl. Comput. Electromagn. Soc. 2021, 35, 1447-1449. [CrossRef]

26. Currie, M.; Mastro, M.A.; Wheeler, V.D. Characterizing the tunable refractive index of vanadium dioxide. Opt. Mater. Express 2017, 7, 1697. [CrossRef]

27. Green, M.A. Self-consistent optical parameters of intrinsic silicon at 300K including temperature coefficients. Sol. Energy Mater. Sol. Cells 2008, 92, 1305-1310. [CrossRef]

28. Aspnes, D.E.; Studna, A.A. Dielectric functions and optical parameters of Si, Ge, GaP, GaAs, GaSb, InP, InAs, and InSb from 1.5 to 6.0 eV. Phys. Rev. B 1983, 27, 985-1009. [CrossRef]

29. Wang, L.; Eliceiri, M.; Deng, Y.; Rho, Y.; Shou, W.; Pan, H.; Yao, J.; Grigoropoulos, C.P. Fast Reversible Phase Change Silicon for Visible Active Photonics. Adv. Funct. Mater. 2020, 30, 1910784. [CrossRef]

30. Kalikka, J.; Akola, J.; Jones, R.O. Simulation of crystallization in Ge2 Sb2 Te5: A memory effect in the canonical phase-Change material. Phys. Rev. B Condens. Matter Mater. Phys. 2014, 90, 1-9. [CrossRef]

31. Skelton, J.M.; Pallipurath, A.R.; Lee, T.H.; Elliott, S.R. Atomistic origin of the enhanced crystallization speed and n-type conductivity in Bi-doped Ge-Sb-Te phase-change materials. Adv. Funct. Mater. 2014, 24, 7291-7300. [CrossRef]

32. Lencer, D.; Salinga, M.; Grabowski, B.; Hickel, T.; Neugebauer, J.; Wuttig, M. A map for phase-change materials. Nat. Mater. 2008, 7, 972-977. [CrossRef]

33. Yang, Z.; Li, Y.; Miao, X. Chalcogenide materials for optoelectronic memory and neuromorphic computing. In Photo-Electroactive Nonvolatile Memories for Data Storage and Neuromorphic Computing; Han, S.-T., Zhou, Y., Eds.; Elsevier: Amsterdam, The Netherlands, 2020; pp. 293-315. ISBN 978-0-12-819717-2.

34. Jiang, W. Nonvolatile and ultra-low-loss reconfigurable mode (De)multiplexer/switch using triple-waveguide coupler with Ge2Sb2Se4Te1 phase change material. Sci. Rep. 2018, 8, 15946. [CrossRef] [PubMed]

35. Zhang, Y.; Chou, J.B.; Li, J.; Li, H.; Du, Q.; Yadav, A.; Zhou, S.; Shalaginov, M.Y.; Fang, Z.; Zhong, H.; et al. Broadband transparent optical phase change materials for high-performance nonvolatile photonics. Nat. Commun. 2019, 10, 1-2. [CrossRef]

36. Gong, Z.; Yang, F.; Wang, L.; Chen, R.; Wu, J.; Grigoropoulos, C.P.; Yao, J. Phase change materials in photonic devices. J. Appl. Phys. 2021, 129. [CrossRef]

37. Faneca, J.; Trimby, L.; Zeimpekis, I.; Delaney, M.; Hewak, D.W.; Gardes, F.Y.; Wright, C.D.; Baldycheva, A. On-chip sub-wavelength Bragg grating design based on novel low loss phase-change materials. Opt. Express 2020, 28, 16394. [CrossRef]

38. Vedeshwar, A.; Optical, A.V.; Stibnite, P.; Journal, S.F. Optical Properties of Amorphous and Polycrystalline Stibnite (Sb2S3) Films To cite this version: HAL Id: Jpa-00249371. J. Phys. III 1995, 5, 1161-1172.

39. Kim, J. Optical Disc and Optical Recording Materials. Polym. Sci. Technol. 1996, 7, 646-654.

40. Dong, W.; Liu, H.; Behera, J.K.; Lu, L.; Ng, R.J.H.; Sreekanth, K.V.; Zhou, X.; Yang, J.K.W.; Simpson, R.E. Wide Bandgap Phase Change Material Tuned Visible Photonics. Adv. Funct. Mater. 2019, 29, 1806181. [CrossRef]

41. Faneca, J.; Zeimpekis, I.; Ilie, S.T.; Bucio, T.D.; Grabska, K.; Hewak, D.W.; Gardes, F.Y. Towards low loss non-volatile phase change materials in mid index waveguides. arXiv 2021, arXiv:2101.11127.

42. Mandal, A.; Cui, Y.; McRae, L.; Gholipour, B. Reconfigurable chalcogenide phase change metamaterials: A material, device, and fabrication perspective. J. Phys. Photonics 2021. [CrossRef]

43. Ruiz de Galarreta, C.; Sinev, I.; Alexeev, A.M.; Trofimov, P.; Ladutenko, K.; Garcia-Cuevas Carrillo, S.; Gemo, E.; Baldycheva, A.; Bertolotti, J.; David Wright, C. Reconfigurable multilevel control of hybrid all-dielectric phase-change metasurfaces. Optica 2020, 7, 476-484. [CrossRef]

44. Fang, Z.; Zheng, J.; Majumdar, A. Non-volatile Integrated Photonics enabled by Broadband Transparent Phase Change Material. In Proceedings of the Conference on Lasers and electro-optics, Washington, DC, USA, 10-15 May 2020; p. JTh2B.3.

45. Delaney, M.; Zeimpekis, I.; Du, H.; Yan, X.; Banakar, M.; Thomson, D.J.; Hewak, D.W.; Muskens, O.L. Non-volatile programmable silicon photonics using an ultralow loss $\mathrm{Sb}_{2} \mathrm{Se}_{3}$ phase change material. arXiv 2021, arXiv:2101.03623.

46. Yu, T.; Ma, X.; Pastor, E.; George, J.K.; Wall, S.; Miscuglio, M.; Simpson, R.E.; Sorger, V.J. All-Chalcogenide Programmable All-Optical Deep Neural Networks. arXiv 2021, arXiv:2102.10398.

47. Fang, Z.; Zheng, J.; Saxena, A.; Whitehead, J.; Chen, Y.; Majumdar, A. Non-Volatile Reconfigurable Integrated Photonics Enabled by Broadband Low-Loss Phase Change Material. Adv. Opt. Mater. 2021, 2002049, 2002049. [CrossRef] 
48. Faneca, J.; Garcia-Cuevas Carrillo, S.; Gemo, E.; de Galarreta, C.R.; Domínguez Bucio, T.; Gardes, F.Y.; Bhaskaran, H.; Pernice, W.H.P.; Wright, C.D.; Baldycheva, A. Performance characteristics of phase-change integrated silicon nitride photonic devices in the $\mathrm{O}$ and $\mathrm{C}$ telecommunications bands. Opt. Mater. Express 2020, 10, 1778. [CrossRef]

49. Eyert, V. The metal-insulator transitions of VO2: A band theoretical approach. Ann. Phys. 2002, 11, 650-704. [CrossRef]

50. Takami, H.; Kanki, T.; Ueda, S.; Kobayashi, K.; Tanaka, H. Filling-controlled Mott transition in W-doped VO 2 . Phys. Rev. B 2012, 85, 205111. [CrossRef]

51. Wegkamp, D.; Stähler, J. Ultrafast dynamics during the photoinduced phase transition in $\mathrm{VO}_{2}$. Prog. Surf. Sci. 2015, 90, 464-502. [CrossRef]

52. Guo, P.; Biegler, Z.; Back, T.; Sarangan, A. Vanadium dioxide phase change thin films produced by thermal oxidation of metallic vanadium. Thin Solid Films 2020, 707, 138117. [CrossRef]

53. Miller, K.J.; Hallman, K.A.; Haglund, R.F.; Weiss, S.M. Silicon waveguide optical switch with embedded phase change material. Opt. Express 2017, 25, 26527-26536. [CrossRef] [PubMed]

54. Clark, J.K.; Ho, Y.; Matsui, H.; Delaunay, J. Optically Pumped Hybrid Plasmonic-Photonic Waveguide Modulator Using the VO2 Metal-Insulator Phase Transition. IEEE Photonics J. 2018, 10, 1-9. [CrossRef]

55. Sweatlock, L.A.; Diest, K. Vanadium dioxide based plasmonic modulators. Opt. Express 2012, 20, 8700-8709. [CrossRef] [PubMed]

56. Pouyan, S.M.; Miri, M.; Sheikhi, M.H. Design and numerical analysis of a high-performance optical modulator based on $\mathrm{Si}^{-\mathrm{VO}_{2}}$ Bragg grating waveguide. Appl. Opt. 2021, 60, 1083-1091. [CrossRef]

57. Chang, T.; Cao, X.; Li, N.; Long, S.; Zhu, Y.; Huang, J.; Luo, H.; Jin, P. Mitigating Deterioration of Vanadium Dioxide Thermochromic Films by Interfacial Encapsulation. Matter 2019, 1, 734-744. [CrossRef]

58. Pitchappa, P.; Kumar, A.; Prakash, S.; Jani, H.; Venkatesan, T.; Singh, R. Chalcogenide Phase Change Material for Active Terahertz Photonics. Adv. Mater. 2019, 31, 1808157. [CrossRef] [PubMed]

59. Chen, X.; Gao, H.; Xing, L.; Dong, W.; Li, A.; Cheng, P.; Liu, P.; Wang, G. Nanoconfinement effects of N-doped hierarchical carbon on thermal behaviors of organic phase change materials. Energy Storage Mater. 2019, 18, 280-288. [CrossRef]

60. Goswami, S.S.; Matula, A.J.; Rath, S.P.; Hedström, S.; Saha, S.; Annamalai, M.; Sengupta, D.; Patra, A.; Ghosh, S.; Jani, H.; et al. Robust resistive memory devices using solution-processable metal-coordinated azo aromatics. Nat. Mater. 2017, 16, 1216-1224. [CrossRef] [PubMed]

61. Clark, J.; Lanzani, G. Organic photonics for communications. Nat. Photonics 2010, 4, 438-446. [CrossRef]

62. Ding, G.; Wang, Y.; Zhang, G.; Zhou, K.; Zeng, K.; Li, Z.; Zhou, Y.; Zhang, C.; Chen, X.; Han, S.-T. 2D Metal-Organic Framework Nanosheets with Time-Dependent and Multilevel Memristive Switching. Adv. Funct. Mater. 2019, 29, 1806637. [CrossRef]

63. van de Burgt, Y.; Lubberman, E.; Fuller, E.J.; Keene, S.T.; Faria, G.C.; Agarwal, S.; Marinella, M.J.; Alec Talin, A.; Salleo, A. A non-volatile organic electrochemical device as a low-voltage artificial synapse for neuromorphic computing. Nat. Mater. 2017, 16, 414-418. [CrossRef]

64. Gu, C.; Lee, J.-S. Flexible Hybrid Organic-Inorganic Perovskite Memory. ACS Nano 2016, 10, 5413-5418. [CrossRef]

65. Chen, J.; Wang, Z.; Wang, Y.; Zhou, Y.; Han, S.-T. Perovskites for phototunable memories and neuromorphic computing. In Photo-Electroactive Nonvolatile Memories for Data Storage and Neuromorphic Computing; Elsevier: Amsterdam, The Netherlands, 2020; pp. 279-292. ISBN 9780128197172.

66. Cho, E.C.; Kim, Y.D.; Cho, K. Thermally responsive poly (N-isopropylacrylamide) monolayer on gold: Synthesis, surface characterization, and protein interaction/adsorption studies. Polym. Guildf 2004, 45, 3195-3204. [CrossRef]

67. Nash, M.E.; Carroll, W.M.; Nikoloskya, N.; Yang, R.; Connell, C.O.; Gorelov, A.V.; Dockery, P.; Liptrot, C.; Lyng, F.M.; Garcia, A.; et al. Straightforward, one-step fabrication of ultrathin thermoresponsive films from commercially available pNIPAm for cell culture and recovery. ACS Appl. Mater. Interfaces 2011, 3, 1980-1990. [CrossRef]

68. Garner, B.W.; Cai, T.; Ghosh, S.; Hu, Z.; Neogi, A. Refractive Index Change Due to Volume-Phase Transition in Polyacrylamide Gel Nanospheres for Optoelectronics and Bio-photonics. Appl. Phys. Express 2009, 2, 057001. [CrossRef]

69. Aleksandrova, R.; Philipp, M.; Müller, U.; Rioboo, R.J.; Ostermeyer, M.; Sanctuary, R.; Müller-Buschbaum, P.; Krüger, J.K. Phase instability and molecular kinetics provoked by repeated crossing of the demixing transition of PNIPAM solutions. Langmuir 2014, 30, 11792-11801. [CrossRef] [PubMed]

70. Depa, K.; Strachota, A.; Šlouf, M.; Hromádková, J. Fast temperature-responsive nanocomposite PNIPAM hydrogels with controlled pore wall thickness: Force and rate of T-response. Eur. Polym. J. 2012, 48, 1997-2007. [CrossRef]

71. Thompson, M.O.; Mayer, J.W.; Cullis, A.G.; Webber, H.C.; Chew, N.G.; Poate, J.M.; Jacobson, D.C. Silicon Melt, Regrowth, and Amorphization Velocities During Pulsed Laser Irradiation. Phys. Rev. Lett. 1983, 50, 896-899. [CrossRef]

72. Hatano, M.; Moon, S.; Lee, M.; Suzuki, K.; Grigoropoulos, C.P. Excimer laser-induced temperature field in melting and resolidification of silicon thin films. J. Appl. Phys. 1999, 87, 36-43. [CrossRef]

73. Demichelis, F.; Minetti-Mezzetti, E.; Tagliaferro, A.; Tresso, E.; Rava, P.; Ravindra, N.M. Optical properties of hydrogenated amorphous silicon. J. Appl. Phys. 1986, 59, 611-618. [CrossRef]

74. Wang, L.; Rho, Y.; Shou, W.; Hong, S.; Kato, K.; Eliceiri, M.; Shi, M.; Grigoropoulos, C.P.; Pan, H.; Carraro, C.; et al. Programming Nanoparticles in Multiscale: Optically Modulated Assembly and Phase Switching of Silicon Nanoparticle Array. ACS Nano 2018, 12, 2231-2241. [CrossRef]

75. Sarwat, S.G. Materials science and engineering of phase change random access memory. Mater. Sci. Technol. 2017, 33, 1890-1906. [CrossRef] 
76. Lee, B.-S.; Shelby, R.M.; Raoux, S.; Retter, C.T.; Burr, G.W.; Bogle, S.N.; Darmawikarta, K.; Bishop, S.G.; Abelson, J.R. Nanoscale nuclei in phase change materials: Origin of different crystallization mechanisms of $\mathrm{Ge}_{2} \mathrm{Sb}_{2} \mathrm{Te}_{5}$ and AgInSbTe. J. Appl. Phys. 2014, 115, 063506. [CrossRef]

77. Kalb, J.A.; Spaepen, F.; Wuttig, M. Kinetics of crystal nucleation in undercooled droplets of Sb- and Te-based alloys used for phase change recording. J. Appl. Phys. 2005, 98, 054910. [CrossRef]

78. Khulbe, P.K.; Hurst, T.; Horie, M.; Mansuripur, M. Crystallization behavior of Ge-doped eutectic Sb_70Te_30 films in optical disks. Appl. Opt. 2002, 41, 6220. [CrossRef]

79. Ríos, C.; Zhang, Y.; Shalaginov, M.Y.; Deckoff-Jones, S.; Wang, H.; An, S.; Zhang, H.; Kang, M.; Richardson, K.A.; Roberts, C.; et al. Multi-Level Electro-Thermal Switching of Optical Phase-Change Materials Using Graphene. Adv. Photonics Res. $2021,2,2000034$. [CrossRef]

80. Wang, Y.; Landreman, P.; Schoen, D.; Okabe, K.; Marshall, A.; Celano, U.; Wong, H.-S.P.; Park, J.; Brongersma, M.L. Electrical tuning of phase-change antennas and metasurfaces. Nat. Nanotechnol. 2021. [CrossRef] [PubMed]

81. Raoux, S.; Burr, G.W.; Breitwisch, M.J.; Rettner, C.T.; Chen, Y.-C.; Shelby, R.M.; Salinga, M.; Krebs, D.; Chen, S.-H.; Lung, H.-L.; et al. Phase-change random access memory: A scalable technology. IBM J. Res. Dev. 2008, 52, 465-479. [CrossRef]

82. Rudé, M.; Simpson, R.E.; Quidant, R.; Pruneri, V.; Renger, J. Active Control of Surface Plasmon Waveguides with a Phase Change Material. ACS Photonics 2015, 2, 669-674. [CrossRef]

83. Bez, R.; Gleixner, R.J.; Pellizzer, F.; Pirovano, A.; Atwood, G. Phase Change Memory Cell Concepts and Designs. In Phase Change Materials: Science and Applications; Raoux, S., Wuttig, M., Eds.; Springer US: Boston, MA, USA, 2009; pp. 355-380, ISBN 978-0-387-84873-0.

84. Phase Change Materials; Raoux, S.; Wuttig, M. (Eds.) Springer US: Boston, MA, USA, 2009; ISBN 978-0-387-84873-0.

85. Wełnic, W.; Wuttig, M. Reversible switching in phase-change materials. Mater. Today 2008, 11, 20-27. [CrossRef]

86. Au, Y.-Y.; Bhaskaran, H.; Wright, C.D. Phase-change devices for simultaneous optical-electrical applications. Sci. Rep. 2017, 7, 9688. [CrossRef]

87. Zhang, H.; Xu, L.; Chen, J.; Zhou, L.; Rahman, B.M.A.; Wu, X.; Lu, L.; Xu, Y.; Xu, J.; Song, J.; et al. Ultracompact Si-GST Hybrid Waveguides for Nonvolatile Light Wave Manipulation. IEEE Photonics J. 2018, 10, 1-10. [CrossRef]

88. Wu, C.; Yu, H.; Li, H.; Zhang, X.; Takeuchi, I.; Li, M. Low-Loss Integrated Photonic Switch Using Subwavelength Patterned Phase Change Material. ACS Photonics 2019, 6, 87-92. [CrossRef]

89. Kato, K.; Kuwahara, M.; Kawashima, H.; Tsuruoka, T.; Tsuda, H. Current-driven phase-change optical gate switch using indium-tin-oxide heater. Appl. Phys. Express 2017, 10, 072201. [CrossRef]

90. Zheng, J.; Fang, Z.; Wu, C.; Zhu, S.; Xu, P.; Doylend, J.K.; Deshmukh, S.; Pop, E.; Dunham, S.; Li, M.; et al. Nonvolatile Electrically Reconfigurable Integrated Photonic Switch Enabled by a Silicon PIN Diode Heater. Adv. Mater. 2020, 32, 1-8. [CrossRef]

91. Zhang, H.; Zhou, L.; Xu, J.; Wang, N.; Hu, H.; Lu, L.; Rahman, B.M.A.; Chen, J. Nonvolatile waveguide transmission tuning with electrically-driven ultra-small GST phase-change material. Sci. Bull. 2019, 64, 782-789. [CrossRef]

92. Zheng, J.; Zhu, S.; Xu, P.; Dunham, S.; Majumdar, A. Modeling Electrical Switching of Nonvolatile Phase-Change Integrated Nanophotonic Structures with Graphene Heaters. ACS Appl. Mater. Interfaces 2020, 12, 21827-21836. [CrossRef]

93. Zhao, Z.; Li, J.; Ling, C.; Zhao, X.; Zhao, Y.; Jin, H. Electric field driven abnormal increase in conductivity of tungsten-doped VO2 nanofilms. Thin Solid Films 2021, 725, 138643-doi10. [CrossRef]

94. Varri, V.S.A.; Tripathi, D.; Vyas, H.S.; Agarwal, P.; Hegde, R.S. Optically-reconfigurable phase change material nanoantennaembedded metamaterial waveguide. Opt. Mater. Express 2021, 11, 988-1003. [CrossRef]

95. Cheng, Z.; Ríos, C.; Pernice, W.H.P.P.; Wright, C.D.; Bhaskaran, H. On-chip photonic synapse. Sci. Adv. 2017, 3, e1700160. [CrossRef] [PubMed]

96. Petronijevic, E.; Sibilia, C. Thin films of phase change materials for light control of metamaterials in the optical and infrared spectral domain. Opt. Quantum Electron. 2020, 52, 110. [CrossRef]

97. Rios, C.; Stegmaier, M.; Cheng, Z.; Youngblood, N.; Wright, C.D.; Pernice, W.H.P.; Bhaskaran, H. Controlled switching of phase-change materials by evanescent-field coupling in integrated photonics [Invited]. Opt. Mater. Express 2018, 8, 2455. [CrossRef]

98. Zhang, J.; Zheng, J.; Xu, P.; Wang, Y.; Majumdar, A. Ultra-low-power nonvolatile integrated photonic switches and modulators based on nanogap-enhanced phase-change waveguides. Opt. Express 2020, 28, 37265. [CrossRef] [PubMed]

99. Ríos, C.; Youngblood, N.; Cheng, Z.; Le Gallo, M.; Pernice, W.H.P.P.; Wright, C.D.; Sebastian, A.; Bhaskaran, H. In-memory computing on a photonic platform. Sci. Adv. 2019, 5, eaau5759. [CrossRef]

100. Feldmann, J.; Youngblood, N.; Li, X.; Wright, C.D.; Bhaskaran, H.; Pernice, W.H.P. Integrated 256 Cell Photonic Phase-Change Memory With 512-Bit Capacity. IEEE J. Sel. Top. Quantum Electron. 2020, 26, 1-7. [CrossRef]

101. Zhang, H.; Yang, X.; Lu, L.; Chen, J.; Rahman, B.M.A.; Zhou, L. Comparison of the phase change process in a GST-loaded silicon waveguide and MMI. Opt. Express 2021, 29, 3503. [CrossRef] [PubMed]

102. Yamada, N. Erasable Phase-Change Optical Materials. MRS Bull. 1996, 21, 48-50. [CrossRef]

103. Yamada, N.; Ohno, E.; Akahira, N.; Nishiuchi, K.; Nagata, K.; Takao, M. High Speed Overwritable Phase Change Optical Disk Material. Jpn. J. Appl. Phys. 1987, 26, 61. [CrossRef]

104. Eilert, S.; Leinwander, M.; Crisenza, G. Phase Change Memory: A New Memory Enables New Memory Usage Models. In Proceedings of the 2009 IEEE International Memory Workshop, Monterey, CA, USA, 10-14 May 2009; pp. 1-2. 
105. Simpson, R.E.; Fons, P.; Kolobov, A.V.; Fukaya, T.; Krbal, M.; Yagi, T.; Tominaga, J. Interfacial phase-change memory. Nat. Nanotechnol. 2011, 6, 501-505. [CrossRef]

106. Ikuma, Y.; Saiki, T.; Tsuda, H. Proposal of a small self-holding $2 * 2$ optical switch using phase-change material. IEICE Electron. Express 2008, 5, 442-445. [CrossRef]

107. Zhang, W.; Li, T. Exploring Phase Change Memory and 3D Die-Stacking for Power/Thermal Friendly, Fast and Durable Memory Architectures. In Proceedings of the 2009 18th International Conference on Parallel Architectures and Compilation Techniques, Raleigh, NC, USA, 12-16 September 2009; pp. 101-112.

108. Dong, X.; Jouppi, N.P.; Xie, Y. PCRAMsim: System-level performance, energy, and area modeling for Phase-Change RAM. In Proceedings of the 2009 IEEE/ACM International Conference on Computer-Aided Design-Digest of Technical Papers, San Jose, CA, USA, 2-5 November 2009; pp. 269-275.

109. Lee, B.C.; Ipek, E.; MutIu, O.; Burger, D. Phase change memory architecture and the quest for scalability. Commun. ACM 2010, 53, 99-106. [CrossRef]

110. Rios, C.; Hosseini, P.; Wright, C.D.; Bhaskaran, H.; Pernice, W.H.P. Tunable Nanophotonic circuits based on phase change materials. In Proceedings of the EPCOS Proceedings, Berlin, Germany, 8-10 September 2013.

111. Rios, C.; Hosseini, P.; Wright, C.D.; Bhaskaran, H.; Pernice, W.H.P. On-Chip Photonic Memory Elements Employing Phase-Change Materials. Adv. Mater. 2014, 26, 1372-1377. [CrossRef]

112. Kuramochi, E.; Notomi, M. Optical memory: Phase-change memory. Nat. Photonics 2015, 9, 712-714. [CrossRef]

113. Ríos, C.; Stegmaier, M.; Hosseini, P.; Wang, D.; Scherer, T.; Wright, C.D.; Bhaskaran, H.; Pernice, W.H.P.P.; Rios, C.; Stegmaier, M.; et al. Integrated all-photonic non-volatile multi-level memory. Nat. Photonics 2015, 9, 725-732. [CrossRef]

114. Cheng, Z.; Ríos, C.; Youngblood, N.; Wright, C.D.; Pernice, W.H.P.P.; Bhaskaran, H. Device-Level Photonic Memories and Logic Applications Using Phase-Change Materials. Adv. Mater. 2018, 30, 1802435. [CrossRef] [PubMed]

115. Farmakidis, N.; Youngblood, N.; Li, X.; Tan, J.; Swett, J.L.; Cheng, Z.; Wright, C.D.; Pernice, W.H.P.; Bhaskaran, H. Plasmonic nanogap enhanced phase-change devices with dual electrical-optical functionality. Sci. Adv. 2019, 5, eaaw2687. [CrossRef] [PubMed]

116. Li, X.; Youngblood, N.; Ríos, C.; Cheng, Z.; Wright, C.D.; Pernice, W.H.; Bhaskaran, H. Fast and reliable storage using a 5 bit, nonvolatile photonic memory cell. Optica 2019, 6, 1. [CrossRef]

117. Bhaskaran, H.; Cheng, Z.; Rios, C.A.; Youngblood, N.; Wright, C.D.; Pernice, W.H. On-chip phase-change photonic memory and computing. In Proceedings of the Active Photonic Platforms IX, San Diego, CA, USA, 24 August 2017.

118. Song, J.-F.; Luo, X.-S.; Lim, A.E.-J.; Li, C.; Fang, Q.; Liow, T.-Y.; Jia, L.-X.; Tu, X.-G.; Huang, Y.; Zhou, H.-F.; et al. Integrated photonics with programmable non-volatile memory. Sci. Rep. 2016, 6, 22616. [CrossRef]

119. Taghinejad, H.; Abdollahramezani, S.; Eftekhar, A.A.; Fan, T.; Hosseinnia, A.H.; Hemmatyar, O.; Dorche, A.E.; Gallmon, A.; Adibi, A. ITO-based microheaters for reversible multi-stage switching of phase-change materials: Towards miniaturized beyond-binary reconfigurable integrated photonics. arXiv 2020, arXiv:2003.04097.

120. Gemo, E.; Faneca, J.; Carrillo, S.G.-C.; Baldycheva, A.; Pernice, W.H.P.; Bhaskaran, H.; Wright, C.D. A plasmonically enhanced route to faster and more energy-efficient phase-change integrated photonic memory and computing devices. J. Appl. Phys. 2021, 129, 110902. [CrossRef]

121. Marković, D.; Mizrahi, A.; Querlioz, D.; Grollier, J. Physics for neuromorphic computing. Nat. Rev. Phys. 2020, 2, 499-510. [CrossRef]

122. Miscuglio, M.; Sorger, V.J. Photonic tensor cores for machine learning. Appl. Phys. Rev. 2020, 7, 031404. [CrossRef]

123. Hughes, T.W.; Minkov, M.; Shi, Y.; Fan, S. Training of photonic neural networks through in situ backpropagation and gradient measurement. Optica 2018, 5, 864. [CrossRef]

124. Burr, G.W.; Shelby, R.M.; Sebastian, A.; Kim, S.; Kim, S.; Sidler, S.; Virwani, K.; Ishii, M.; Narayanan, P.; Fumarola, A.; et al. Neuromorphic computing using non-volatile memory. Adv. Phys. X 2017, 2, 89-124. [CrossRef]

125. Tan, J.Y.S.; Cheng, Z.; Li, X.; Youngblood, N.; Ali, U.E.; Wright, C.D.; Pernice, W.H.P.; Bhaskaran, H. Monadic Pavlovian associative learning in a backpropagation-free photonic network. arXiv 2020, arXiv:2011.14709.

126. Song, S.; Miller, K.D.; Abbott, L.F. Competitive Hebbian learning through spike-timing-dependent synaptic plasticity. Nat. Neurosci. 2000, 3, 919-926. [CrossRef] [PubMed]

127. Caporale, N.; Dan, Y. Spike Timing-Dependent Plasticity: A Hebbian Learning Rule. Annu. Rev. Neurosci. 2008, 31, 25-46. [CrossRef] [PubMed]

128. Prezioso, M.; Merrikh-Bayat, F.; Hoskins, B.D.; Adam, G.C.; Likharev, K.K.; Strukov, D.B. Training and operation of an integrated neuromorphic network based on metal-oxide memristors. Nature 2015, 521, 61-64. [CrossRef]

129. Rajendran, B.; Alibart, F. Neuromorphic Computing Based on Emerging Memory Technologies. IEEE J. Emerg. Sel. Top. Circuits Syst. 2016, 6, 198-211. [CrossRef]

130. Wright, C.D.; Au, Y.-Y.; Aziz, M.M.; Bhaskaran, H.; Cobley, R.; Rodriguez-Hernandez, G.; Hosseini, P.; Pernice, W.H.P.; Wang, L. Novel applications possibilities for phase-change materials and devices. In Proceedings of the EPCOS Proceedings, Berlin, Germany, 8-10 September 2013.

131. Wu, C.; Yu, H.; Lee, S.; Peng, R.; Takeuchi, I.; Li, M. Programmable phase-change metasurfaces on waveguides for multimode photonic convolutional neural network. Nat. Commun. 2021, 12, 1-8. [CrossRef] 
132. Feldmann, J.; Youngblood, N.; Karpov, M.; Gehring, H.; Li, X.; Stappers, M.; Le Gallo, M.; Fu, X.; Lukashchuk, A.; Raja, A.S.; et al. Parallel convolutional processing using an integrated photonic tensor core. Nature 2021, 589, 52-58. [CrossRef] [PubMed]

133. Zhang, H.; Zhou, L.; Xu, J.; Lu, L.; Chen, J.; Rahman, B.M.A. All-optical synapses based on silicon microring resonators actuated by the phase change material Ge2Sb2Te5. In Proceedings of the Conference on Lasers and Electro-Optics, Washington, DC, USA, 5-10 May 2019; p. STh4H.2.

134. Guo, X.; Xiang, J.; Zhang, Y.; Su, Y. Integrated Neuromorphic Photonics: Synapses, Neurons, and Neural Networks. Adv. Photonics Res. 2021, 2000212. [CrossRef]

135. Deng, L. The MNIST Database of Handwritten Digit Images for Machine Learning Research. IEEE Signal Process. Mag. 2012, 29, 141-142. [CrossRef]

136. Chakraborty, I.; Saha, G.; Roy, K. Photonic In-Memory Computing Primitive for Spiking Neural Networks Using Phase-Change Materials. Phys. Rev. Appl. 2019, 11, 014063. [CrossRef]

137. Carrillo, S.G.C.; Gemo, E.; Li, X.; Youngblood, N.; Katumba, A.; Bienstman, P.; Pernice, W.; Bhaskaran, H.; Wright, C.D. Behavioral modeling of integrated phase-change photonic devices for neuromorphic computing applications. APL Mater. 2019, 7. [CrossRef]

138. Li, X.; Youngblood, N.; Zhou, W.; Feldmann, J.; Swett, J.; Aggarwal, S.; Sebastian, A.; Wright, C.D.; Pernice, W.; Bhaskaran, H. On-chip Phase Change Optical Matrix Multiplication Core. In Proceedings of the 2020 IEEE International Electron Devices Meeting (IEDM), San Francisco, CA, USA, 12-18 December 2020; pp. 7.5.1-7.5.4.

139. Zhou, L.; Zhang, H.; Lu, L.; Chen, J.; Zhou, Z.; Rahman, B.M.A. Ultra-Compact Multi-Level Optical Switching with Non-Volatile GST Phase Change. In Proceedings of the 2019 24th OptoElectronics and Communications Conference (OECC) and 2019 International Conference on Photonics in Switching and Computing (PSC), Fukuoka, Japan, 7-11 July 2019; pp. 1-3.

140. Sanchez, L.; Lechago, S.; Gutierrez, A.; Sanchis, P. Analysis and Design Optimization of a Hybrid $\mathrm{VO}_{2} /$ Silicon $2 \times 2$ Microring Switch. IEEE Photonics J. 2016, 8, 1-9. [CrossRef]

141. Markov, P.; Marvel, R.E.; Conley, H.J.; Miller, K.J.; Haglund, R.F.; Weiss, S.M. Optically Monitored Electrical Switching in VO 2. ACS Photonics 2015, 2, 1175-1182. [CrossRef]

142. Briggs, R.M.; Pryce, I.M.; Atwater, H.A. Compact silicon photonic waveguide modulator based on the vanadium dioxide metal-insulator phase transition. Opt. Express 2010, 18, 11192. [CrossRef] [PubMed]

143. Ryckman, J.D.; Diez-Blanco, V.; Nag, J.; Marvel, R.E.; Choi, B.K.; Haglund, R.F.; Weiss, S.M. Photothermal optical modulation of ultra-compact hybrid $\mathrm{Si}-\mathrm{VO}_{2}$ ring resonators. Opt. Express 2012, 20, 13215. [CrossRef] [PubMed]

144. Nag, J.; Ryckman, J.D.; Hertkorn, M.T.; Choi, B.K.; Haglund, R.F., Jr.; Weiss, S.M. Ultrafast Compact Silicon-Based Ring Resonator Modulators Using Metal-Insulator Switching of Vanadium Dioxide; Witzigmann, B., Henneberger, F., Arakawa, Y., Osinski, M., Eds.; SPIE OPTO: San Francisco, CA, USA, 2010.

145. Zheng, J.; Khanolkar, A.; Xu, P.; Colburn, S.; Deshmukh, S.; Myers, J.; Frantz, J.; Pop, E.; Hendrickson, J.; Doylend, J.; et al. GST-on-silicon hybrid nanophotonic integrated circuits: A non-volatile quasi-continuously reprogrammable platform. Opt. Mater. Express 2018, 8, 1551. [CrossRef]

146. Abdollahramezani, S.; Hemmatyar, O.; Taghinejad, H.; Krasnok, A.; Kiarashinejad, Y.; Zandehshahvar, M.; Alù, A.; Adibi, A. Tunable nanophotonics enabled by chalcogenide phase-change materials. Nanophotonics 2020, 9, 1189-1241. [CrossRef]

147. Wang, X.; Qi, H.; Hu, X.; Yu, Z.; Ding, S.; Du, Z.; Gong, Q. Advances in Photonic Devices Based on Optical Phase-Change Materials. Molecules 2021, 26, 2813. [CrossRef]

148. Jain, P.; Tanaka, D.; Tsuda, H. Mach Zehnder interferometer optical switch using phase-change material. In Proceedings of the 2012 International Conference on Photonics in Switching (PS), Ajaccio, France, 11-14 September 2012; pp. 1-3.

149. Kruger, B.A.; Joushaghani, A.; Poon, J.K.S. Design of electrically driven hybrid vanadium dioxide (VO_2) plasmonic switches. Opt. Express 2012, 20, 23598. [CrossRef]

150. Rudé, M.; Pello, J.; Simpson, R.E.; Osmond, J.; Roelkens, G.; van der Tol, J.J.G.M.; Pruneri, V. Optical switching at 1.55 m in silicon racetrack resonators using phase change materials. Appl. Phys. Lett. 2013, 103, 141119. [CrossRef]

151. Kim, J.T. CMOS-compatible hybrid plasmonic modulator based on vanadium dioxide insulator-metal phase transition. Opt. Lett. 2014, 39, 3997. [CrossRef]

152. Joushaghani, A.; Jeong, J.; Paradis, S.; Alain, D.; Stewart Aitchison, J.; Poon, J.K.S. Wavelength-size hybrid Si-VO 2 waveguide electroabsorption optical switches and photodetectors. Opt. Express 2015, 23, 3657. [CrossRef]

153. Diana, L.D.S.; Juan, F.C.; Escutia, A.R.; Kilders, P.S. Ultra-compact electro-absorption $\mathrm{VO}_{2}-S i$ modulator with TM to TE conversion. J. Opt. 2017, 19, 035401. [CrossRef]

154. Wong, H.M.K.; Helmy, A.S. Performance Enhancement of Nanoscale $\mathrm{VO}_{2}$ Modulators Using Hybrid Plasmonics. J. Light. Technol. 2018, 36, 797-808. [CrossRef]

155. Song, J.; Ghosh, S.; Zhang, H.; Zhou, L.; Rahman, B.M.A. Design, optimization, and performance evaluation of GSST clad low-loss non-volatile switches. Appl. Opt. 2019, 58, 8687. [CrossRef] [PubMed]

156. Zhang, Z.; Yang, J.; Bai, W.; Han, Y.; He, X.; Zhang, J.; Huang, J.; Chen, D.; Xu, S.; Xie, W. Chipscale plasmonic modulators and switches based on metal-insulator-metal waveguides with Ge2Sb2Te5. J. Nanophotonics 2019, 13, 1. [CrossRef]

157. Faneca, J.; Bucio, T.D.; Gardes, F.Y.; Baldycheva, A. O-band N-rich silicon nitride MZI based on GST. Appl. Phys. Lett. 2020, 116, 093502. [CrossRef] 
158. Ríos, C.; Du, Q.; Zhang, Y.; Popescu, C.-C.; Shalaginov, M.Y.; Miller, P.; Roberts, C.; Kang, M.; Richardson, K.A.; Gu, T.; et al. Ultra-compact nonvolatile photonics based on electrically reprogrammable transparent phase change materials. arXiv 2021, arXiv:2105.06010.

159. Jeyaselvan, V.; Pal, A.; Anil Kumar, P.S.; Selvaraja, S.K. Thermally-induced optical modulation in a vanadium dioxide-on-silicon waveguide. OSA Contin. 2020, 3, 132. [CrossRef]

160. Seo, G.; Kim, B.-J.; Ko, C.; Cui, Y.; Lee, Y.W.; Shin, J.-H.; Ramanathan, S.; Kim, H.-T. Voltage-Pulse-Induced Switching Dynamics in $\$ \backslash$ hbox $\{\mathrm{VO}\} \_\{2\} \$$ Thin-Film Devices on Silicon. IEEE Electron Device Lett. 2011, 32, 1582-1584. [CrossRef]

161. Jerry, M.; Shukla, N.; Paik, H.; Schlom, D.G.; Datta, S. Dynamics of electrically driven sub-nanosecond switching in vanadium dioxide. In Proceedings of the 2016 IEEE Silicon Nanoelectronics Workshop (SNW), Honolulu, HI, USA, 12-13 June 2016; pp. 26-27.

162. Shibuya, K.; Ishii, K.; Atsumi, Y.; Yoshida, T.; Sakakibara, Y.; Mori, M.; Sawa, A. Switching dynamics of silicon waveguide optical modulator driven by photothermally induced metal-insulator transition of vanadium dioxide cladding layer. Opt. Express 2020, 28, 37188. [CrossRef]

163. Madaras, S.E.; Creeden, J.A.; Lahneman, D.J.; Harbick, A.; Beringer, D.B.; Qazilbash, M.M.; Novikova, I.; Lukaszew, R.A. Dynamics of the blue pump-induced ultrafast insulator-to-metal transition and relaxation in $\mathrm{VO}_{2} / \mathrm{TiO}_{2}$ and $\mathrm{VO}_{2} / \mathrm{TiO}_{2}: \mathrm{Nb}$ thin films. Opt. Mater. Express 2020, 10, 1393. [CrossRef]

164. Haddadpour, A.; Nezhad, V.F.; Yu, Z.; Veronis, G. Highly compact magneto-optical switches for metal-dielectric-metal plasmonic waveguides. Opt. Lett. 2016, 41, 4340. [CrossRef]

165. Piao, X.; Yu, S.; Park, N. Control of Fano asymmetry in plasmon induced transparency and its application to plasmonic waveguide modulator. Opt. Express 2012, 20, 18994. [CrossRef] [PubMed]

166. Liang, H.; Soref, R.; Mu, J.; Majumdar, A.; Li, X.; Huang, W.-P. Simulations of Silicon-on-Insulator Channel-Waveguide Electrooptical $2 \times 2$ Switches and $1 \times 1$ Modulators Using a Ge $\mathrm{Sb}_{2} \mathrm{Te}_{5}$ Self-Holding Layer. J. Light. Technol. 2015, 33, 1805-1813. [CrossRef]

167. Liang, H.; Soref, R.; Mu, J.; Li, X.; Huang, W.-P. Electro-optical phase-change $2 \times 2$ switching using three- and four-waveguide directional couplers. Appl. Opt. 2015, 54, 5897. [CrossRef] [PubMed] 